
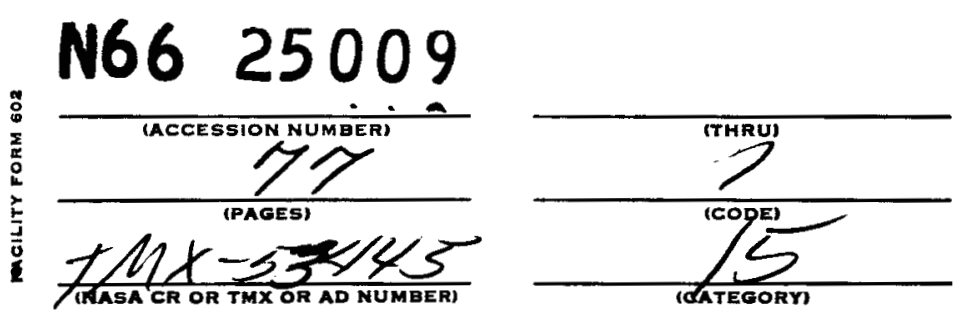

\title{
HEAT TREATMENT OF TITANIUM AND TITANIUM ALLOYS
}

By F. F. Schmidt and R. A. Wood

\section{NASA}

George C. Marshall

Space Flight Center,

GPO PRICE $\mathbf{S}$

CFSTI PRICE(S)

Huntsville, Alabama 
HEAT TREATMENT OF TITANIUM AND TITANIUM ALLOYS

By

F. F. Schmidt and R. A. Wood $*$

ABSTRACT

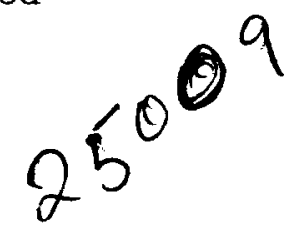

This report reviews present heat treatment practices for titanium and titanium alloys. It describes the methods, techniques, and equipment currently employed in the thermal treatment of titanium materials, and the necessary processing considerations and precautions that govern these treatments. The metallurgical background illustrating the principles used in titanium heat treatment is also discussed with respect to alloy classifications, structures, and hardening mechanisms.

*Principal Investigators, Battelle Memorial Institute, Contract No. DA-01-021-AMC-11651(Z)

NASA-GEORGE C. MARSHALL SPACE FLIGHT CENTER 
NASA-GEORGE C. MARSHALL SPACE FLIGHT CENTER

TECHNICAL MEMORANDUM X-53445

HEAT TREATMENT OF TITANIUM AND TITANIUM ALLOYS

By

F. F. Schmidt and R. A. Wood

Prepared for

Manufacturing Engineering Laboratory

In Cooperation with

Technology Utilization Office

Under the supervision of

Redstone Scientific Information Center

U. S. Army Missile Command

Redstone Arsenal, Alabama

MSFC Order No, H-76715

Report No. RSIC-493

Subcontracted to

Battelle Memorial Institute

505 King Avenue

Columbus, Ohio

Contract No. DA-01-021-AMC-11651(Z) 


\section{PREFACE}

This report is one of a series of state-of-the-art reports being prepared by Battelle Memorial Institute, Columbus, Ohio, under Contract No. DA-01-021-AMC-1165l(Z), in the general field of materials fabrication.

This report on heat treatment of titanium and titanium alloys is intended to provide information useful to designers, fabricators, and users of titanium materials. The detailed discussions involving the metallurgical background, methods, techniques, equipment, and precautions are considered to be reliable guides underlying current practice employed in the thermal treatments of titanium and titanium alloys.

The report summarizes information collected from books, technical conferences, reports on Government contracts, and interviews with technical personnel actively engaged in titanium heat treatment. A total of 27 references, most of which are year 1965, are cited. 
SUMMARY .

INTRODUCTION

METALLURGICAL BEHAVIOR OF TITANIUM ALLOYS . . . 2

Classification of Titanium Alloys . • . . . . . . . . 2

Structure of Titanium Alloys . . . . . . . . . . . . 5

Alpha Alloys . . . . . . . . . . . . . . 5

Alpha-Beta Alloys . . . . . . . . . . . . 77

Beta Alloys. . . . . . . . . . . . . . . 9

Hardening Mechanism in Titanium Alloys . . . . . . 9

Stress Relief and Annealing Titanium Alloys . . . . . 12

TYPICAL THERMAL TREATMENTS AND PROPERTIES

OF REPRESENTATIVE TITANIUM ALLOYS . . . . . . 14

Alpha Alloy - Ti-5Al-2.5Sn . . . . . . . . . . 19

Structure . . . . . . . . . . . . . . . 19

Stress-Relief Annealing. . . . . . . . . . . . 19

Annealing . . . . . . . . . . . . . . 20

Strengthening Heat Treatments . . . . . . . 20

Thermal Stability. . . . . . . . . . . . . 21

Alpha-Beta Alloy - Ti-6Al-4V . . . . . . . . . 21

Structure . . . . . . . . . . . . . . . 21

Stress-Relief Annealing. . . . . . . . . . . 22

Annealing . . . . . . . . . . . . . . . 23

Strengthening Heat Treatments . . . . . . . 23

Hardenability. • . . . . . . • . . . . 23

Solution Annealing . . . . . . . • . • .

Aging Heat Treatments . . . . . . . . . 23

Thermal Stability. . . . . . . . . . . . 26

Beta Alloy - Ti-13V-11Cr-3Al. . . . . . . . 26

Structure . . . . . . . . . . . . . . 26

Stress-Relief Annealing. . . . . . . . . . 27

Annealing . . . . . . . . . . . . . . . 27

Strengthening Heat Treatments . . . . . . . 27

Hardenability. . . . . . . . . . . . . 27

Solution Annealing . . . . . . . . . . . 27

Aging Heat Treatments . . . . . . . . . 29

Thermal Stability. . . . . . . . . . . . 29 
TABLE OF CONTENTS

(Continued)

Page

TITANIUM HEAT-TREATMENT PRACTICE. . . . . . . 30

Contamination . . . . . . . . . . . . . . 30

Effect on Properties. . . . . . . . . . . . 31

Oxidation . . . . . . . . . . . . . . . 33

Corrosion . . . . . . . . . . . . . . . 37

Contamination Control. . . . . . . . . . . 38

Furnacing . . . . . . . . . . . . . . . . 45

Heat-Treatment Techniques . . . . . . . . . 49

CONCLUSIONS AND RECOMMENDATIONS • • • • • • . 55

REFERENCES . . . • . • . . . . . . . . . 56 
1. Principal Types of Titanium-Alloy Constitution Diagrams • • • • • • • • • • • • • • . 3

2. Microstructures of Fully Annealed Titanium . . . . 6

3. The Effect of Solution-Treatment Temperature on the Microstructures of the Alpha-Beta Alloy $\mathrm{Ti}-4.4 \mathrm{Mn}$. . . . . . . . . . . . . .

4. Representative Hardness Curve for an Alpha-Beta Alloy Quenched From Alpha-Beta Field and Aged at $800 \mathrm{~F}$

5. Effect of Cooling Rate on Phase Relationships and Properties of a Typical Heat-Treatable Titanium Alloy

6. Effect of Time and Temperature on the Relief of Residual Stress in Ti-5Al-2.5Sn . . . . . . . . 19

7. The Phase Relationships for Ti-6Al-4V . . . . . 21

8. Effect of Time and Temperature on the Relief of Residual Stress in Ti-6Al-4V

9. End-Quench Hardenability Curves for Ti-6Al-4V . .

10. The Effect of Aging on Hardness of a Ti-6Al-4V Specimen End Quenched From 1550 F

11. The Effect of Section Size on the Tensile Properties of $\mathrm{Ti}-6 \mathrm{Al}-4 \mathrm{~V}$

12. The Effect of Solution Temperature on Tensile Properties of Ti-6Al-4V • . . . . . . . . .

13. The Effect of Delayed Water Quenching From 1750 and $1550 \mathrm{~F}$ on the Tensile Properties of Ti-6Al-4V . . . 


\section{LIST OF ILLUSTRATIONS}

(Continued)

Figure

Title

Page

14. The Effect of Aging Time at $900 \mathrm{~F}$ on the Tensile

Properties of Ti-6Al-4V Solution Treated at $1550 \mathrm{~F}$

15. Phase Diagram of B-l20VCA With Variable Chromium Content $\left(\mathrm{Ti}-13 \mathrm{~V}-\mathrm{Cr}-3 \mathrm{Al}-0.5 \mathrm{O}_{2}\right)$. . . . . . . 28

16. Phase Diagram of B-l20VCA With Variable Aluminum Content $\left(\mathrm{Ti}-13 \mathrm{~V}-11 \mathrm{Cr}-\mathrm{Al}-0.5 \mathrm{O}_{2}\right)$. . . . . . .

17. TTT Diagram for Ti-13V-11Cr-3Al-0. 15O 2 as Determined by Metallographic Techniques . . . . . .

18. Effect of Solution Temperature on the Annealed and Annealed-Plus-Aged Hardness of $\mathrm{Ti}-13 \mathrm{~V}-11 \mathrm{Cr}-3 \mathrm{Al}$

19. Effect of Thermal Exposure at $600 \mathrm{~F}$ on the Tensile Properties of Annealed-and-Worked $\mathrm{Ti}-13 \mathrm{~V}-11 \mathrm{Cr}-3 \mathrm{Al}$

20. Effect of Carbon, Oxygen, and Nitrogen on Tensile

21. Effect of Carbon, Oxygen, and Nitrogen on Vickers

22. Effect of Interstitials on Toughness of Iodide Titanium

23. Characteristics of Hydrogen Embrittlement in Alpha Alloys, From Data on Iodide Titanium.

24. Oxidation Rates of Titanium in Oxygen in the 800 to 1100 F Range

25. Comparison of the Metal Losses of Commercial Titanium, Ti-5Al-2.5Sn, and Ti-4Al-4Mn Heated in Air for 8 Hours 


\section{LIST OF ILLUSTRATIONS \\ (Continued)}

Figure

Title

Page

26. Summary of Hardness-Penetration Data for Unalloyed Titanium Heated for Various Times in Air at $1600 \mathrm{~F}$. . . . . . . . . . . . . . 37

27. Technique for Estimating the Depth of Contamination of Commercial Titanium From Combinations of Time and Temperature of Exposure to Air . . . . .

28. For Estimating the Depth of Contamination of Ti-5Al-2.5Sn From Combination of Time and Temperature of Exposure to Air . . . . . . .

29. For Estimating the Depth of Contamination of Ti-4Al$4 \mathrm{Mn}$ From Combinations of Time and Temperature of Exposure to Air . . . . . . . . . . .

30. Vertical Gantry Type of Furnace. . . . . . . . 48

31. Car Bottom Type of Furnace . . . . . . . . . 48

32. Hot Sizing of Titanium . . . . . . . . . 53

33. Time-Temperature-Per Cent Stress Relief RelationShip for Ti-6Al-4V . . . . . . . . . . . 


\section{LIST OF TABLES}

Table

I. Heat Treatment and Selected Properties of Titanium

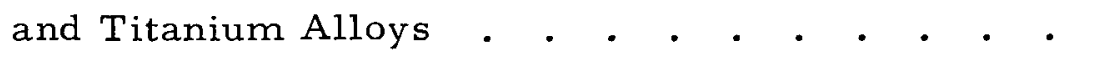

II. Producer Designations and Forms Available for Titanium and Titanium Alloys . . . . . . . 18

III. Tensile Properties of Annealed Ti-5Al-2.5Sn

Extruded at $1700 \mathrm{~F}$. . . . . . . . . . 20

IV. Effect of Temperature on the Oxide-Film Thickness of Commercially Pure Titanium Heated in Air for $1 / 2$ Hour 


\title{
TECHNICAL MEMORANDUM X-53445
}

HEAT TREATMENT OF TITANIUM AND TITANIUM ALLOYS

\author{
SUMMARY
}

The occurrence of an allotropic transformation in pure titanium controls the type of structures that can be produced by the heat treatment of titanium-rich alloys and hence increases the range of mechanical properties that can be obtained from the alloys. Titanium alloys are divided into three classes depending on the predominant phases present: alpha or near alpha, alpha plus beta, or beta. Specific heattreatment practice and its effect on properties for a representative $\alpha$-alloy (Ti-5Al-2.5Sn), $\alpha-\beta$ alloy $(\mathrm{Ti}-6 \mathrm{Al}-4 \mathrm{~V})$, and $\beta$-alloy (Ti-13V$11 \mathrm{Cr}-3 \mathrm{Al}$ ) are discussed in detail. Typical thermal treatments for other common alloys of interest including the so-called "super-alpha" alloys are tabulated.

Titanium is chemically very active at elevated temperatures, and reacts readily with oxygen, nitrogen, carbon, and hydrogen in a furnace atmosphere. Furthermore, all contamination reactions cause degradation of properties and, with the exception of the hydrogen reaction, are irreversible. Because of oxidation, heating times are kept as short as is required to perform the heat treatment. Because of its very reactive nature, titanium should be heat treated under conditions as clean as possible which means keeping the workpiece separated from all foreign substances, such as organics, iron oxides, refractory debris, etc. Titanium alloys are also subject to stress corrosion in the presence of chlorides (which might be residual from such things as chlorinated cleaning solutions) when subsequently exposed to temperatures above about $550 \mathrm{~F}$.

Thermal treatments for titanium materials are normally carried out in conventional gas-fired, oil-fired, or electric furnaces readily available to industry. The atmosphere in the furnace should be free from water vapor and should be slightly oxidizing. Both water vapor and incompletely burned fuel vapor can react with titanium to form atomic hydrogen which is readily absorbed by titanium. These problems may be reduced by using protective coatings and/or more inert atmospheres, or completely eliminated by using vacuum treatment. Reducing atmospheres or endothermic atmospheres should not be used in heat-treating titanium. 
Most titanium materials that are in the semifinished or finished., condition are fixtured in jigs to control distortion during the heattreatment operation. Stress-relieving temperatures are frequently used to straighten and creep form titanium parts in hot-sizing presses.

A number of recommendations that attempt to identify problem areas and advancements needed to further titanium heat-treatment technology are included in this report.

\section{INTRODUCTION}

At the present time (1965), titanium and titanium alloys are used extensively in a variety of applications, ranging in sophistication from critical missile and aircraft components to corrosion-resistant anodizing racks. Manufacturing concerns that have had extensive experience in fabricating this material have found that it is only slightly more difficult to handle than are most of the other structural materials. As with most structural materials, certain procedures must be followed to produce high-quality end items from titanium. This report presents the metallurgical background underlying the heat treatment of titanium and titanium alloys, specific thermal treatments applied to the various alloys, and methods, techniques, and precautions used in actual practice. Specific recommendations identifying problem areas and advancements needed to further titanium heattreatment technology are also outlined.

\section{METALLURGICAL BEHAVIOR OF TITANIUM ALLOYS}

The various thermal treatments applied to titanium and its alloys to develop desirable structural characteristics for metalworking and end-product properties are best understood from a fundamental consideration of titanium metallurgy. Therefore, this section of the report is intended to illustrate the principles used in titanium heat treatment.

\section{CLASSIFICATION OF TITANIUM ALLOYS}

Titanium has two crystal structures. Alpha titanium, the lowtemperature modification, has a close-packed hexagonal structure which is stable up to about $1625 \mathrm{~F}$. Beta titanium, the hightemperature allotrope, has a body-centered cubic structure and is 
stable from the $1625 \mathrm{~F}$ transformation temperature up to the melting point of $3035 \mathrm{~F}$. The temperature at which $\alpha$-titanium begins to transform to beta is raised by the alloying of $\alpha$-stabilizing elements and lowered by the alloying of $\beta$-stabilizing elements. The temperature at which the last remaining $\alpha$-titanium transforms to $\beta$-titanium on heating is called the $\beta$-transus. Titanium alloys are classified as containing principally $\alpha$-phase, $\beta$-phase, or a mixture of $\alpha$ - and $\beta$-phases.

The three principal types of phase diagrams for titanium alloys are illustrated in Figure 1. The alpha peritectoid type of system is characteristic of titanium alloys with aluminum, carbon, nitrogen, and oxygen. These elements have a greater solubility in the $\alpha$-phase than in the $\beta$-phase. The addition element stabilizes the $\alpha$-phase and the $\alpha-\beta$ region is elevated to high temperatures with increasing $\alpha$-alloy content. Tin, zirconium, and possibly antimony appear to be neutral, stabilizing neither $\alpha$-phase nor $\beta$-phase preferentially. In general, however, these elements are considered $\alpha$-stabilizing elements.
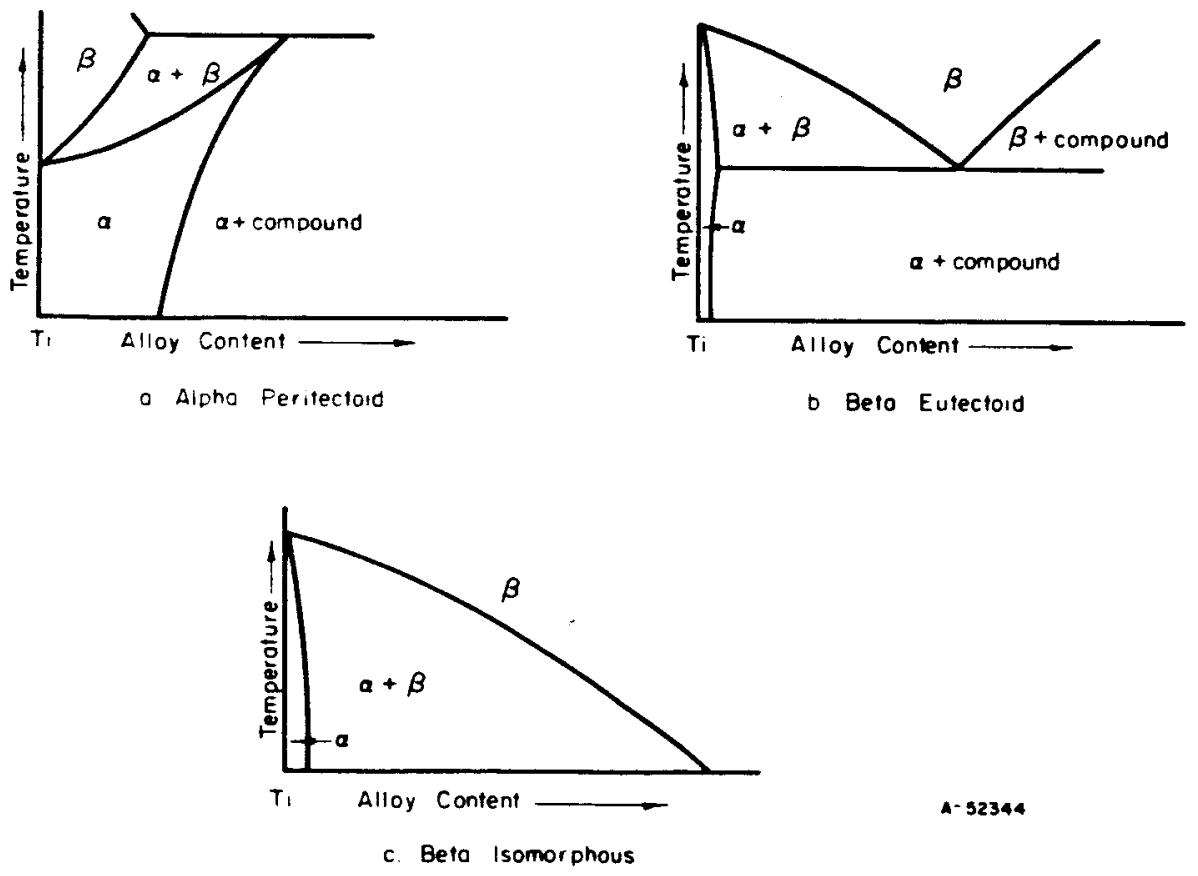

FIGURE 1. PRINCIPAL TYPES OF TITANIUM-ALLOY CONSTITUTION DIAGRAMS 
The $\beta$-eutectoid type of system is characteristic of titanium alloys with such additions as manganese, iron, chromium, nickel, copper, and silicon. These $\beta$-stabilizing elements dissolve preferentially in the $\beta$-phase causing a lowering of the transus temperature with increasing alloy content. A eutectoid reaction occurs in this type of system at a temperature between the transformation temperature of pure titanium and room temperature in which the $\beta$-phase decomposes to form the $\alpha$-solid solution and an intermediate phase richer in the alloying element - usually an intermetallic compound. Although under equilibrium conditions, chromium, manganese, and iron form $\beta-$ eutectoid systems. The eutectoid reaction in these alloys is very sluggish, and in actual practice, these alloys behave as if the eutectoid reaction did not occur. Additions of copper and silicon form true eutectoid type of alloys.

The beta isomorphous type of system includes alloys with molybdenum, vanadium, tantalum, and columbium. These elements are appreciably more soluble in the $\beta$-phase than in the $\alpha$-phase and the $\beta /(\alpha-\beta)$ and $\alpha /(\alpha-\beta)$ boundaries are depressed towards lower temperatures with increasing $\beta$-concentration. Sufficient amounts of these additions render $\beta$-titanium stable at room temperature. In a binary alloy, there is a minimum amount of any $\beta$-stabilizing element that enables the retention of 100 per cent metastable beta on quenching from the $\beta$-phase field. For the common $\beta$-stabilizers these amounts are shown below (Ref. 1) *:

\begin{tabular}{lr}
$\begin{array}{c}\text { Stabilizing } \\
\text { Element }\end{array}$ & \multicolumn{2}{c}{$\begin{array}{c}\text { to Produce } \\
\text { Metastable Beta }\end{array}$} \\
\cline { 3 - 3 } Iron & 4 \\
Copper & 12 \\
Manganese & 6 \\
Chromium & 7 \\
Molybdenum & 11 \\
Vanadium & 15 \\
Columbium & 36 \\
Tantalum & 40
\end{tabular}

In the foregoing discussion, consideration has been given to those conditions which exist favoring $\alpha$-type or $\beta$-type of alloy structures. Another most important group of titanium alloys are those that contain both $\alpha$ - and $\beta$-phases. These are termed $(\alpha-\beta)$ type of alloys. Since the $\beta$-phase is not retained in the absence of a $\beta$-stabilizing alloy

* References are given on page 56 of this report. 
addition, such an element is an essential constitutent of the $\alpha-\beta$ type of alloys. In addition to the $\beta$-stabilizing elements, $\alpha$ - $\beta$-type of alloys may contain an $\alpha$-soluble element, such as aluminum, to add greater strength to the $\alpha$-phase. The $\alpha$-soluble elements are also soluble to an appreciable extent in the $\beta$-phase. Thus, $\alpha-\beta$ types of alloys are not only affected by the amount of $\beta$-stabilizing element present but also by the presence of $\alpha$-phase stabilizing additions.

The metallurgical changes that alloying brings about in titanium form the basis for dividing titanium alloys into three classes, depending on whether they are normally used in a condition in which they consist entirely of $\alpha$-phase, entirely of the $\beta$-phase, or a mixture of the two phases.

\section{STRUCTURE OF TITANIUM ALLOYS}

Alpha Alloys. In $\alpha$-alloys, the $\beta$-phase transforms completely to the $\alpha$-phase during cooling through the transformationtemperature range. Either a nucleation and growth Widmanstätten type alpha or a martensitic type alpha may be formed. The martensitic structure formed during rapid cooling is designated as $\alpha^{\prime}$. The $\alpha^{\prime}$ is of equilibrium composition even when the alloys are rapidly quenched from temperatures above the $\beta$-transus. (Ref. 2) The alloys are, therefore, not responsive to heat treatment.

Alpha-stabilizing additions of aluminum in excess of about 6 per cent introduce the probability of a superlattice structure which has been identified as an ordered $\mathrm{Ti}_{3} \mathrm{Al}$ structure $\left(\alpha_{2}\right)$. The ordering may be dilute long range, but its effect is generally to increase strength and creep resistance, while decreasing fracture toughness and perhaps hot workability. (Ref. 3). Thus, long holding times or slow cooling in the critical ordering temperature range $(950$ to $1250 \mathrm{~F}$ for the near- $\alpha$ Ti-8Al-1Mo-1V alloy) should be avoided in the fabrication or heat-treatment cycles for $\alpha$-stabilized titanium alloys containing appreciable amounts of aluminum. (Ref. 1)

As indicated above, the Ti-8Al-1Mo-1 V alloy is not a pure $\alpha$-alloy. It is an $\alpha-\beta$ alloy with so little $\beta$-stabilizer content, it is often called a near- $\alpha$ alloy. Another popular term used for this grade and other near- $\alpha$ grades (such as the Ti-679 alloy) is "super-alpha". Two all- $\alpha$ grades, $\mathrm{Ti}-7 \mathrm{Al}-12 \mathrm{Zr}$ and $\mathrm{Ti}-5 \mathrm{Al}-5 \mathrm{Sn}-5 \mathrm{Zr}$, also are called superalphas. The heat treatment and metallurgy of the latter follow exactly that of other pure or all- $\alpha$ alloys. The heat treatment and metallurgy of the $\beta$-containing super-alpha alloys, $\mathrm{Ti}-8 \mathrm{Al}-1 \mathrm{Mo}-1 \mathrm{~V}$ and 
Ti-679 are in general similar to $\alpha-\beta$ alloys but differ because of the small $\beta$-stabilizer content.

The microstructure of $\alpha$-tjtanium alloys consists essentially of 100 per cent $\alpha$-phase. Alpha alloys, such as commercially pure unalloyed titanium and $\mathrm{Ti}-5 \mathrm{Al}-2.5 \mathrm{Sn}$, contain a small amount of $\beta$-phase as a result of impurities, such as iron; however, this is not in sufficient quantity to alter their transformation behavior.

Depending upon the method of treating the metal, $\alpha$-titanium can appear in several modifications. Three different microstructures of fully annealed unalloyed titanium are shown in Figure 2: equiaxed alpha, Widmanstätten alpha, and martensitic alpha $\left(\alpha^{\prime}\right)$. The latter two are frequently lumped together under the name acicular alpha. Widmanstätten alpha occurs by transformation of beta to alpha on cooling through the transformation-temperature range at a moderately slow rate. A more rapid cooling rate leads to the development of martinsitic alpha $\left(\alpha^{\prime}\right)$. Both forms of acicular alpha are therefore transformation products. Equiaxed alpha on the other hand, can only be produced by recrystallization of material that has been significantly deformed in the $\alpha$-field. The presence of acicular alpha is therefore an indication that the material has been heated into the $\beta$-field. (Ref. 4)

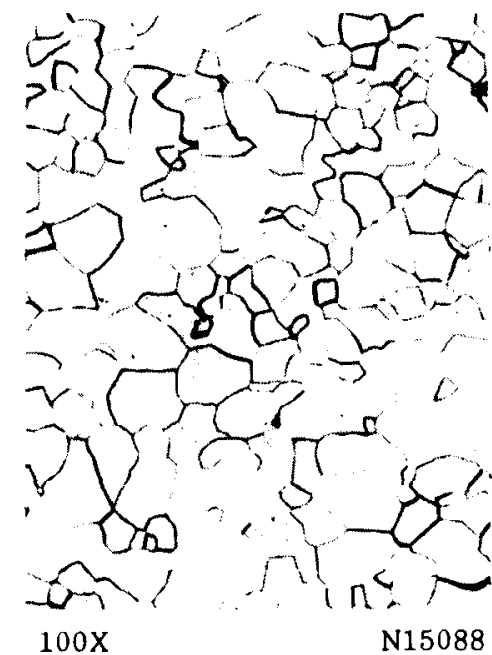

a. Equiaxed Alpha

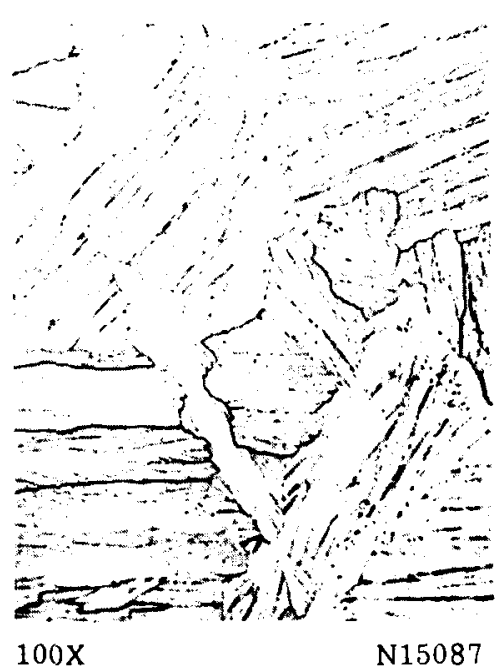

b. Widmanstatten Alpha

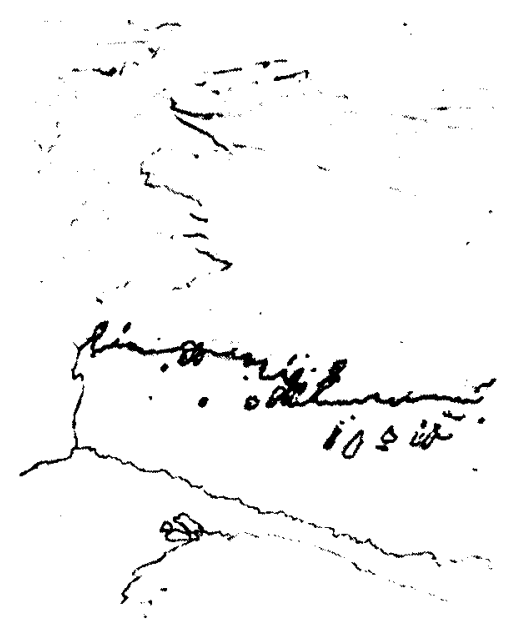

N15085 Annealed 1 hour at $1290 \mathrm{~F}$

FIGURE 2. MICROSTRUCTURES OF FULLY ANNEALED TITANIUM (REF . 4) 
Alpha-Beta Alloys. Depending upon the $\beta$-stabilization elements and their relative amounts, $\alpha-\beta$ alloys may be classed as strongly or weakly $\beta$-stabilized. By definition, martensitic types of $\alpha-\beta$ alloys contain $\alpha^{\prime}$ after quenching from $\alpha-\beta$ or $\beta$-phase fields. The amount of $\alpha^{\prime}$ produced by quenching decreases with increasing $\beta$ stabilizing-alloy content. Therefore, weakly stabilized $\beta$-alloys are generally martensitic. On the other hand, alloys containing a higher percentage of $\beta$-stabilizer will retain metastable beta upon quenching from the $\alpha-\beta$ or $\beta$-phase fields.

Although $\alpha-\beta$ alloys are strengthened by quenching from temperatures above the $\beta$-transus, such treatments are not used in commercial heat-treating practice. Rather, solution treatments, followed by aging, are used to strengthen $\alpha-\beta$ titanium alloys. The solution treatment consists of (1) heating to temperatures approaching, but below, the $\beta$-transus, (2) holding at this temperature for a given period of time, and (3) cooling rapidly to room temperature. The solutiontreatment temperature determines the amount of $\beta$-phase that is present in the alloy and the composition of the $\beta$-phase. This is illustrated in Figure 3. By proper temperature selection and rapid cooling, the $\beta$-phase, which is metastable below the solutiontreatment temperature, is retained to room temperature. The alloys are then aged at temperatures in the range of 900 to $1100 \mathrm{~F}$. During aging, $\alpha$-titanium precipitates from the $\beta$-phase and the alloy is strengthened. In addition, as precipitation of alpha takes place, the remaining $\beta$-phase is enriched in $\beta$-stabilizing content and becomes stable. (Ref. 5)

Processing and thermal history also affect the microstructure of $\alpha-\beta$ alloys (Figure 3). If the alloys are worked and heat treated below the $\beta$-transus, fine-grained equiaxed microstructures result. These structures give the best combinations of strength and ductility. If $\alpha-\beta$ alloys are worked or heated above the $\beta$-transus, large $\beta$-grains form. During subsequent cooling, the $\beta$-grains transform to a final structure that depends on alloy content and cooling rate. Acicular or martensitic structures are formed when alloys with low $\beta$-stabilizing contents are cooled or quenched. With higher $\beta$-stabilizing contents, transformation is more sluggish and the acicular structure becomes finer and, at high enough alloy contents, finally disappears. After annealing, or after solution treatments and aging, alloys with large primary $\beta$-grains have the same strength, but less ductility, than fine-grained alloys in similar conditions. Because of the lower ductility, largegrain structures are generally objectionable. (Ref. 5) The lower ductility associated with acicular $\alpha-\beta$ alloys, in conjunction with the tendency for $\omega$-transformation on cooling accompanying the heating of 


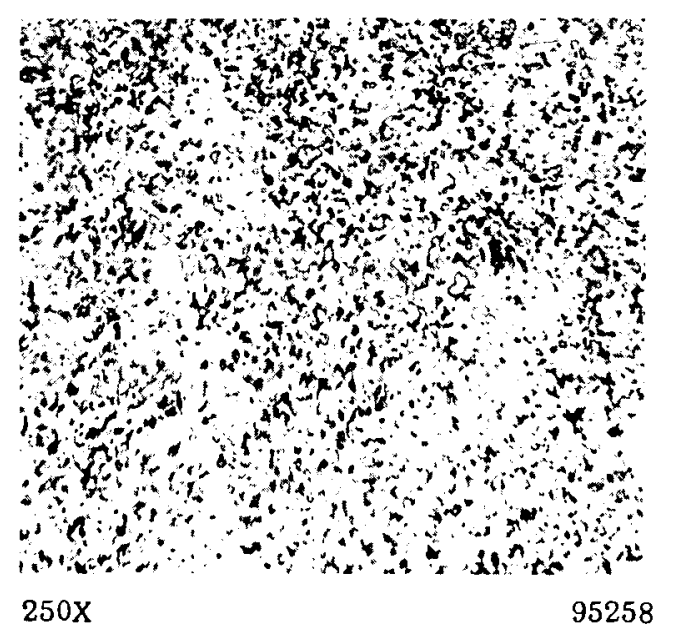

a. Annealed 1 Hour at $1200 \mathrm{~F}$

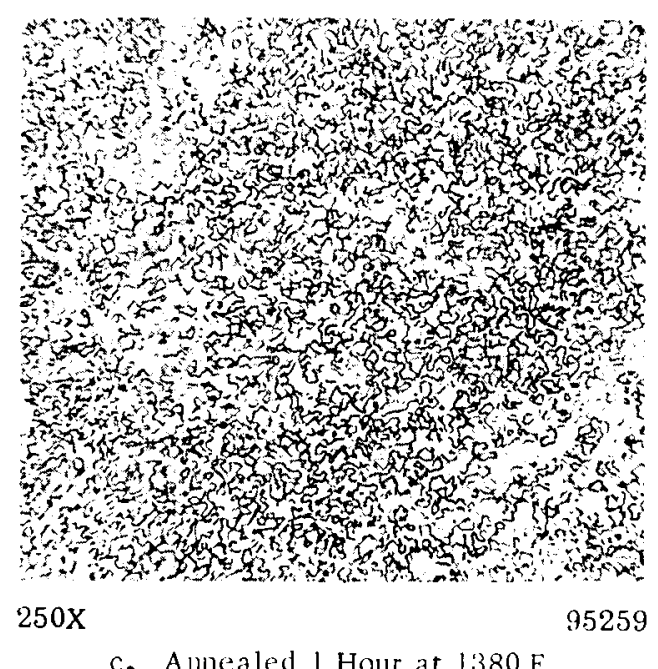

c. Annealed 1 Hour at 1:380 F

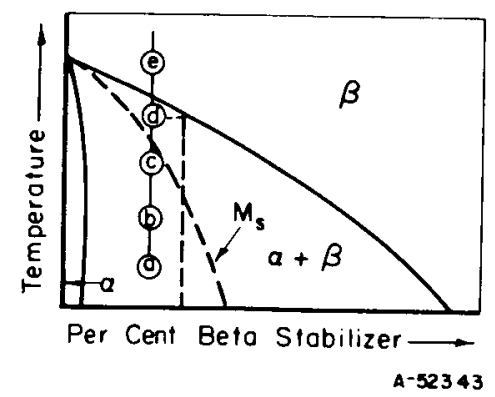

FIGURE 3. THE EFFECT OF SOLUTION-TREATMENT TEMPERATURE ON THE MICROSTRUCTURES OF THE ALPHA-BETA ALLOY Ti-4.4Mn (REF. 5)

All specincens water quenched after anneal.

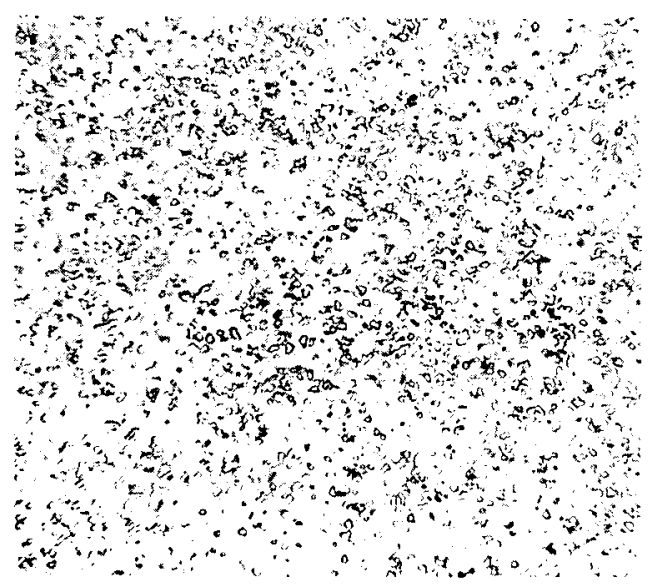

$250 \mathrm{X}$

95265

b. Annealed 1 Hour at $1290 \mathrm{~F}$

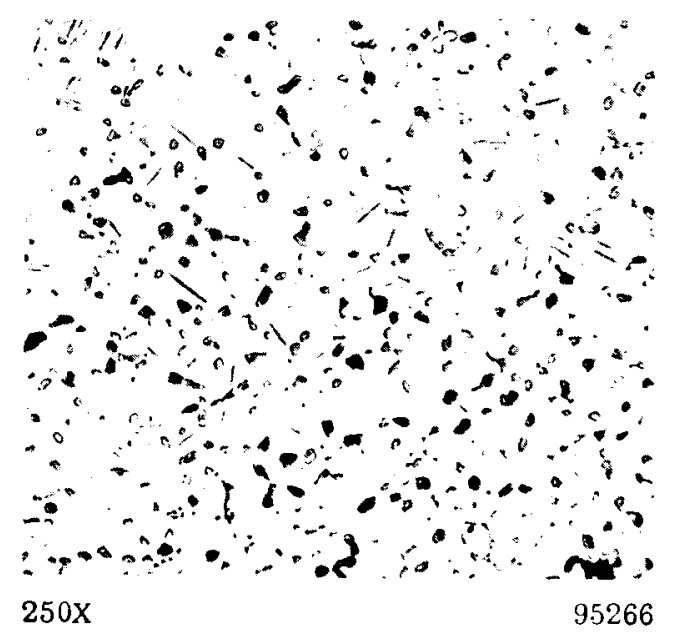

d. Annealed 1 Hour at $1490 \mathrm{~F}$

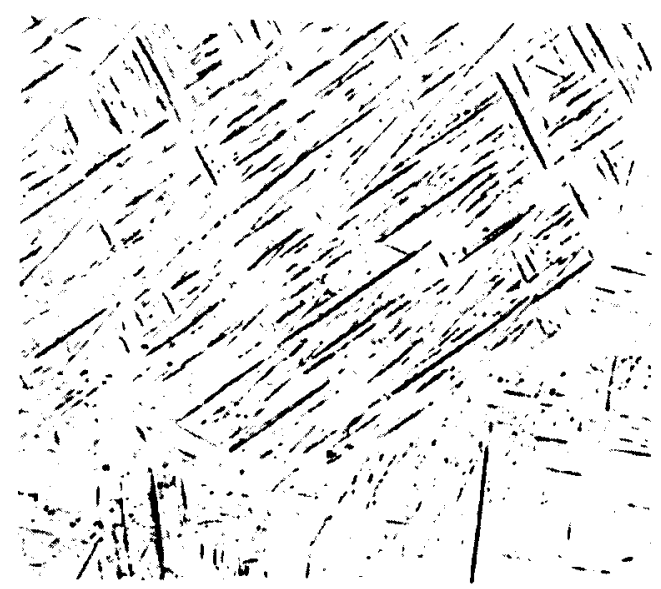

$250 \mathrm{X}$

95250

c. Antlealed 1 Hour at 1530 F 
If the $\beta$-stabilizer present in the alloy is less than the critical àmount, metastable beta will not be retained after quenching from the solution-temperature range. Rather, it transforms to martensite $\left(\alpha^{\prime}\right)$ by a shear mechanism. Martensite formation is characteristic of weakly $\beta$-stabilized alloys, particularly at high solution temperature. At low solution temperatures some $\beta$-phase will be retained in the metastable condition on quenching if the solute composition of the beta is near the critical. However, most of the beta will transform to martensite. Any metastable beta present will transform during aging to alpha in the manner described in Figure 4.

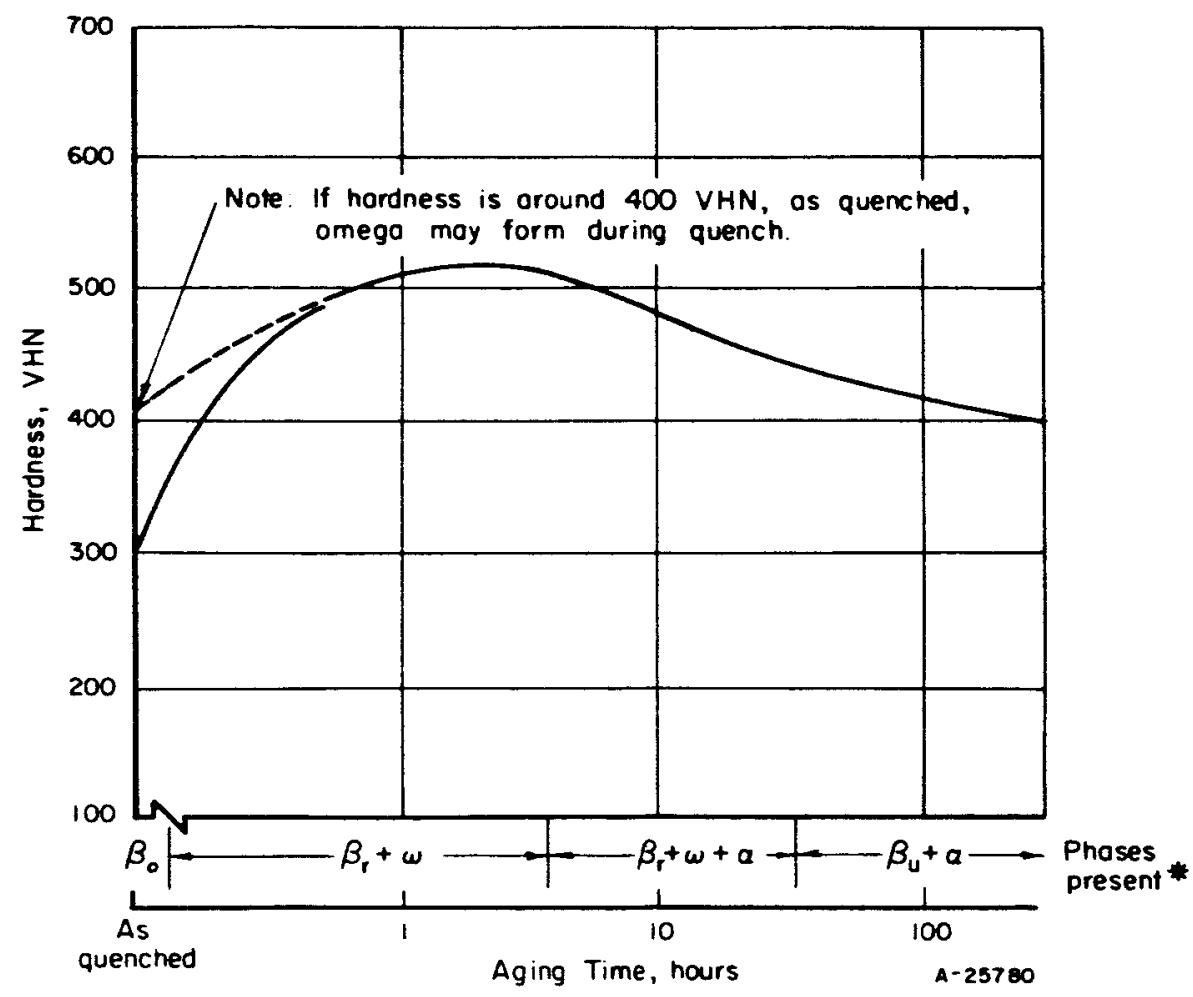

FIGURE 4. REPRESENTATIVE HARDNESS CURVE FOR AN ALPHA-BETA ALLOY QUENCHED FROM ALPHA-BETA FIELD AND AGED AT $800 \mathrm{~F}$ (REF. 7)

*Some primary alpha would also be present unless alloy is quenched from beta field.

Alpha prime is not an equilibrium structure in $\alpha-\beta$ and $\beta$-alloys. Since more alloying addition can be maintained in $\alpha^{-}$than the equilibrium amount soluble in $\alpha$ (Ref. 2), alpha prime in highly 
alloyed materials upon aging reverts to alpha, producing property changes, including hardening. The mechanism is not completely understood and appears to vary depending on alloy composition. The manifestation of this in some alloys has been observed by the development of a finely dispersed precipitate within the $\alpha^{-}$-needle, after aging between 900 and $1400 \mathrm{~F}$. (Ref. 1)

\section{STRESS RELIEF AND ANNEALING TITANIUM ALLOYS}

Stress relieving and annealing treatments are common practice for all commercial titanium alloys. These treatments are normally employed to condition the metal for subsequent fabrication or to restore desired combinations of ductility and stability after fabrication.

A stress-relief treatment is a treatment which produces a relaxation of residual stresses induced from mechanical operations or weldjoining operations. Stress relieving is conducted at the lowest temperature at which stresses may be reduced to desired levels in practical times. In addition, treatments are selected so that oxidation and undesirable metallurgical factors are minimized. The effectiveness of a particular stress-relief treatment depends quite strongly upon alloy type and alloy concentration. Recommended timetemperature combinations for stress relieving several of the more common alloys are given below: (Ref. 1)

\begin{tabular}{|c|c|c|c|}
\hline \multirow[b]{2}{*}{ Alloy } & \multirow[b]{2}{*}{$\begin{array}{l}\text { Alloy } \\
\text { Type }\end{array}$} & \multicolumn{2}{|c|}{ Stress-Relieving Conditions } \\
\hline & & $\begin{array}{l}\text { Time, } \\
\text { hours }\end{array}$ & $\begin{array}{c}\text { Temperature, } \\
F\end{array}$ \\
\hline Commercial titanium & $\alpha$ & $1 / 4$ to 4 & $900-1100$ \\
\hline $\mathrm{Ti}-5 \mathrm{Al}-2.5 \mathrm{Sn}$ & $\alpha$ & $1 / 4$ to 4 & $1000-1200$ \\
\hline $\mathrm{Ti}-8 \mathrm{Al}-1 \mathrm{Mo}-1 \mathrm{~V}$ & Near $\alpha$ & $1 / 2$ to 5 & $1100-1300$ \\
\hline $\mathrm{Ti}-8 \mathrm{Mn}$ & $\alpha-\beta$ & $1 / 4$ to 1 & $900-1100$ \\
\hline $\mathrm{Ti}-4 \mathrm{Al}-3 \mathrm{Mo}-1 \mathrm{~V}$ & $\alpha-\beta$ & $1 / 2$ to 8 & $900-1050$ \\
\hline $\mathrm{Ti}-6 \mathrm{Al}-4 \mathrm{~V}$ & $\alpha-\beta$ & 1 to 24 & $900-1200$ \\
\hline $\mathrm{Ti}-6 \mathrm{Al}-6 \mathrm{~V}-2 \mathrm{Sn}$ & $\alpha-\beta$ & 1 to 8 & $900-1200$ \\
\hline $\mathrm{Ti}-13 \mathrm{~V}-11 \mathrm{Cr}-3 \mathrm{Al}$ & $\beta$ & $1 / 4$ to $1 / 2$ & $1300-1350$ \\
\hline $\begin{array}{l}\text { Precautions shoul } \\
\beta \text {-stabilized alloys at } \\
\text { this temperature, app } \\
\text { are then allowed to }\end{array}$ & $\begin{array}{l}\text { aken to } \\
\text { ratures } \\
\text { le amou }\end{array}$ & $\begin{array}{l}\text { stress reli } \\
\text { higher tha } \\
\text { beta will } \\
\text { will be re }\end{array}$ & $\begin{array}{l}\text { ng strongly } \\
50 \mathrm{~F} \text {. Above } \\
\text { If If the parts } \\
\text { med. If, at any } \\
\text { mperatures }\end{array}$ \\
\hline
\end{tabular}


alloys of this type into the $\beta$-field has occasionally been referred to as " $\beta$-embrittlement". This term is no longer in common usage.

Acicular $\alpha-\beta$ structures are generally observed in weldments and in some extruded and forged components. Alloy compositions have been modified to make these structures less objectionable.

Beta Alloys. A $\beta$-phase alloy that is thermodynamically stable at room temperature can only be obtained in titanium-alloy systems in which the addition element is, itself, body-centered cubic at room temperature and in which a continuous series of $\beta$-phase solid solution exists at all concentrations of the addition element (Ref. 6). Alloys of this type are represented by the $\beta$-isomorphous system in which the $\beta$-stabilizing additions of vanadium, columbium, tantalum, and/or molybdenum suppress the formation of $\alpha$-phase such that $\beta$-phase decomposition occurs below room temperature (stable beta). Metastablebeta alloys, such as $\mathrm{Ti}-13 \mathrm{~V}-1 \mathrm{Cr}-3 \mathrm{Al}$, are so heavily $\beta$-stabilized that the $\beta$ to $\alpha$-transformation is very sluggish and the alloy remains 100 per cent beta when cooled from above the $\beta$-transus temperature (about $1325 \mathrm{~F}$ ). Air cooling from the solution temperature is sufficiently rapid to retain $\beta$-phase in a metastable condition. Thus, solution treating is synonymous with annealing for alloys of this type. (Ref. 1)

\section{HARDENING MECHANISM IN TITANIUM ALLOYS}

In strongly $\beta$-stabilized alloys, the tendency is great for metastable beta to be retained on quenching. As the $\beta$-stabilization increases and the solution temperature decreases this tendency is further enhanced. During subsequent elevated-temperature exposure, as in aging heat treatment, the $\beta$-phase may partially decompose. The metastable-beta decomposition during aging may be summarized as follows: (Ref. 7)

$$
\begin{aligned}
& \beta_{\mathrm{O}} \rightarrow \beta_{\mathrm{r}}+\omega \\
& \beta_{\mathrm{r}}+\omega \rightarrow \beta_{\mathrm{r}}+\omega+\alpha \\
& \beta_{\mathrm{r}}+\omega+\alpha \rightarrow \beta_{\mathrm{u}}+\alpha \\
& \beta_{\mathrm{u}}+\alpha \rightarrow \alpha+\mathrm{Ti}_{\mathrm{x}} \mathrm{M}_{\mathrm{y}} \text { (in active eutectoid systems), }
\end{aligned}
$$

where 
$\beta_{0}=\beta$-phase of original alloy content that exists at the solution temperature and retained on quenching

$\beta_{u}=\beta$-phase of the equilibrium or pseudo-equilibrium alloy content that exists at the aging temperature

$\beta_{\mathbf{r}}=\beta$-phase of the alloy content intermediate between that of $\beta_{\mathrm{o}}$ and $\beta_{\mathrm{u}}$ (During the aging process, $\beta$-phase gradually becomes richer in $\beta$-stabilizer elements, and eventually the composition reaches that value indicated by the $\beta$-transus.)

$\omega=$ transition phase having a complex structure

$\alpha=$ equilibrium alpha phase

$\mathrm{Ti}_{\mathrm{x}} \mathrm{M}_{\mathrm{y}}=$ intermetallic compound phase.

In many alloys $\omega$ is difficult to avoid on quenching or in the initial stages of reheating for aging. Omega formation is most likely to occur at the lower aging temperatures (below $900 \mathrm{~F}$ ). It can be avoided by severe quenching and rapid reheating to the higher agingtemperature range. An aging temperature is normally selected that is high enough to insure that the $\omega$-reaction is carried to completion in practical times and low enough to favor sufficient $\alpha$-nucleation sites for the formation of a fine to medium $\alpha$-precipitate. (Ref. 1)

An understanding of the nature of the phase changes that take place when a $\beta$-stabilized titanium alloy is quenched and subsequently aged may be obtained from Figure 4. This diagram may be applied, in principle, to many titanium alloys. In the quenched condition, the alloy contains a large percentage of beta and has comparatively low hardness unless the quench is not rapid enough to suppress the formation of omega. (Ref. 7)

After aging a short time at temperatures below about $1000 \mathrm{~F}$, the $\beta$-phase starts to transform to omega and the alloy is hardened and strengthened drastically. This high hardness persists for long times at temperatures below $800 \mathrm{~F}$. At aging temperatures between 800 and $1100 \mathrm{~F}$, the alloy overages in practical lengths of time as the hardness curve shows. This partial softening produces the useful mechanical properties for which titanium alloys are noted. It is brought about by the completion of the transformation of omega to alpha, leaving a fine, uniform dispersion of alpha in a $\beta$-matrix. (Ref. 7) 
higher than about $600 \mathrm{~F}$, the beta could partially decompose to $\dot{\omega}$-phase and the parts might be seriously embrittled. (Ref. 7)

It is thus apparent that for titanium-alloy sheet which is being hot formed or stress relieved, adequate temperature control is very necessary. If the stress-relief annealing temperature is too low, e.g., 800 or $900 \mathrm{~F}$, the stresses may not be sufficiently relieved. If the temperature is too high, metastable beta might form, and the part may fail during service if omega precipitates from the beta.

In $\alpha$-alloys, annealing produces a recrystallized equiaxed grain structure for materials worked in the $\alpha$-field. Annealing of $\alpha-\beta$ or $\beta$-alloys produces a sluggish or stable $\beta$-phase and, in $\alpha$ - $\beta$ alloys, a slightly increased amount of alpha. Annealing treatments of $\alpha-\beta$ alloys are normally designed to develop maximum thermal stability. Both the composition and the amount of $\beta$-phase in a given $\alpha-\beta$ alloy depend upon the temperature to which the alloy is heated and the rate at which it is cooled. For example, in the Ti-8Mn alloy, the beta which exists at $1325 \mathrm{~F}$ contains about 13 per cent manganese; at $1525 \mathrm{~F}$ the beta contains only 8 per cent manganese, but much more is present. The composition of the beta determines its stability. Therefore, if the alloy were quenched from $1325 \mathrm{~F}$, the beta retained would be more stable than if the alloy were quenched from $1525 \mathrm{~F}$. To obtain maximum stability of the beta phase, the alloy must be cooled very slowly through the temperature range in which the $\alpha$-phase is rejected most readily. Since alpha will dissolve very little manganese, it is obvious that the remaining beta must become enriched and, therefore, more stable. Thus, for example, the beta phase in the Ti-8Mn alloy cooled slowly to $1150 \mathrm{~F}$ would have a manganese content of about 16 per cent. (Ref. 7)

Slow cooling through the temperature range 1300 to $1100 \mathrm{~F}$ is generally used by titanium producers for mill products. In Figure 5 the effects of three different cooling rates on the microstructures and properties of an $\alpha-\beta$ alloy are summarized. This shows that a potential source of $\omega$-embrittlement is in the strongly $\beta$-stabilized alloys which have not been cooled slowly enough from the final rolling temperature. Such material is unstable and, if reheated for hot forming, will very likely become embrittled. Less strongly $\beta$-stabilized alloys, such as $\mathrm{Ti}-6 \mathrm{Al}-4 \mathrm{~V}$, which do not undergo an $\omega$ reaction can be cooled more rapidly from the stabilizing treatment. 


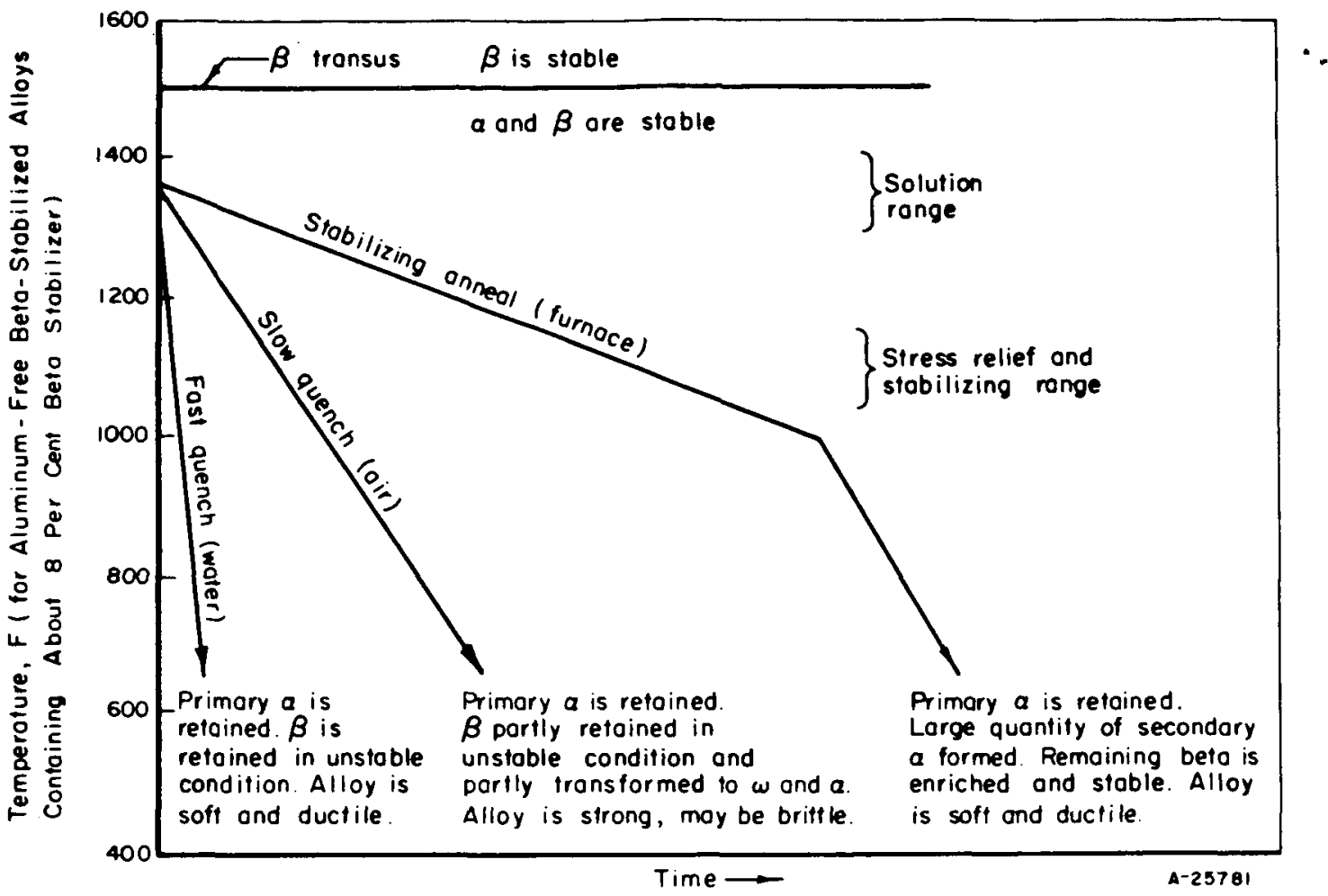

FIGURE 5. EFFECT OF COOLING RATE ON PHASE RELATIONSHIPS AND PROPERTIES OF A TYPICAL HEAT TREATABLE TITANIUM ALLOY (REF. 7)

\section{TYPICAL THERMAL TREATMENTS AND PROPERTIES OF REPRESENTATIVE TITANIUM ALLOYS}

Although currently there are about 30 titanium alloys commercially available, about 10 of these account for 85 to 90 per cent of all applications. This group includes three grades of unalloyed titanium and the alloys, $\mathrm{Ti}-5 \mathrm{Al}-2.5 \mathrm{Sn}, \mathrm{Ti}-6 \mathrm{Al}-4 \mathrm{~V}, \mathrm{Ti}-8 \mathrm{Al}-1 \mathrm{Mo}-1 \mathrm{~V}$, Ti-6Al-6V-2Sn, and Ti-13V-1 lCr-3Al. (Ref. 4) The Ti-6Al-4V alloy is by far the most-used grade (about 60 to 65 per cent of all titanium used). (Ref. 8) The Ti-5Al-2. 5Sn ( $\alpha$-representative), Ti-6Al-4V $(\alpha-\beta$ representative), and $\mathrm{Ti}-13 \mathrm{~V}-1 \mathrm{lCr}-3 \mathrm{Al}(\beta-\mathrm{representative)}$ alloys are discussed in the following sections in detail with respect to specific heat-treatment practice and effects on properties. The most common thermal treatments for these and all other titanium alloys normally encountered, together with typical mechanical properties obtainable, are summarized in Table I. The producer designations and the forms available for the various titanium grades are listed in Table II. 


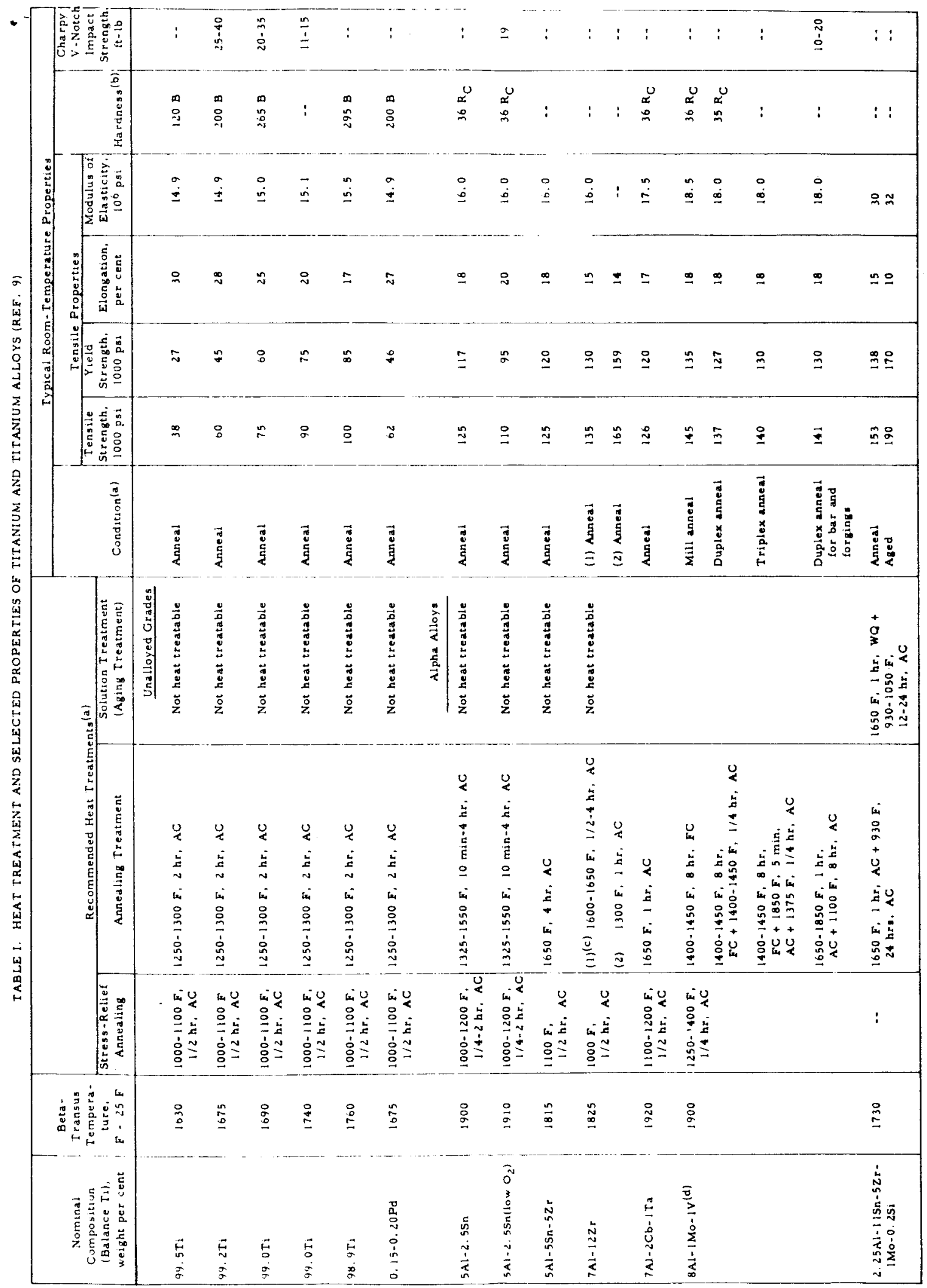




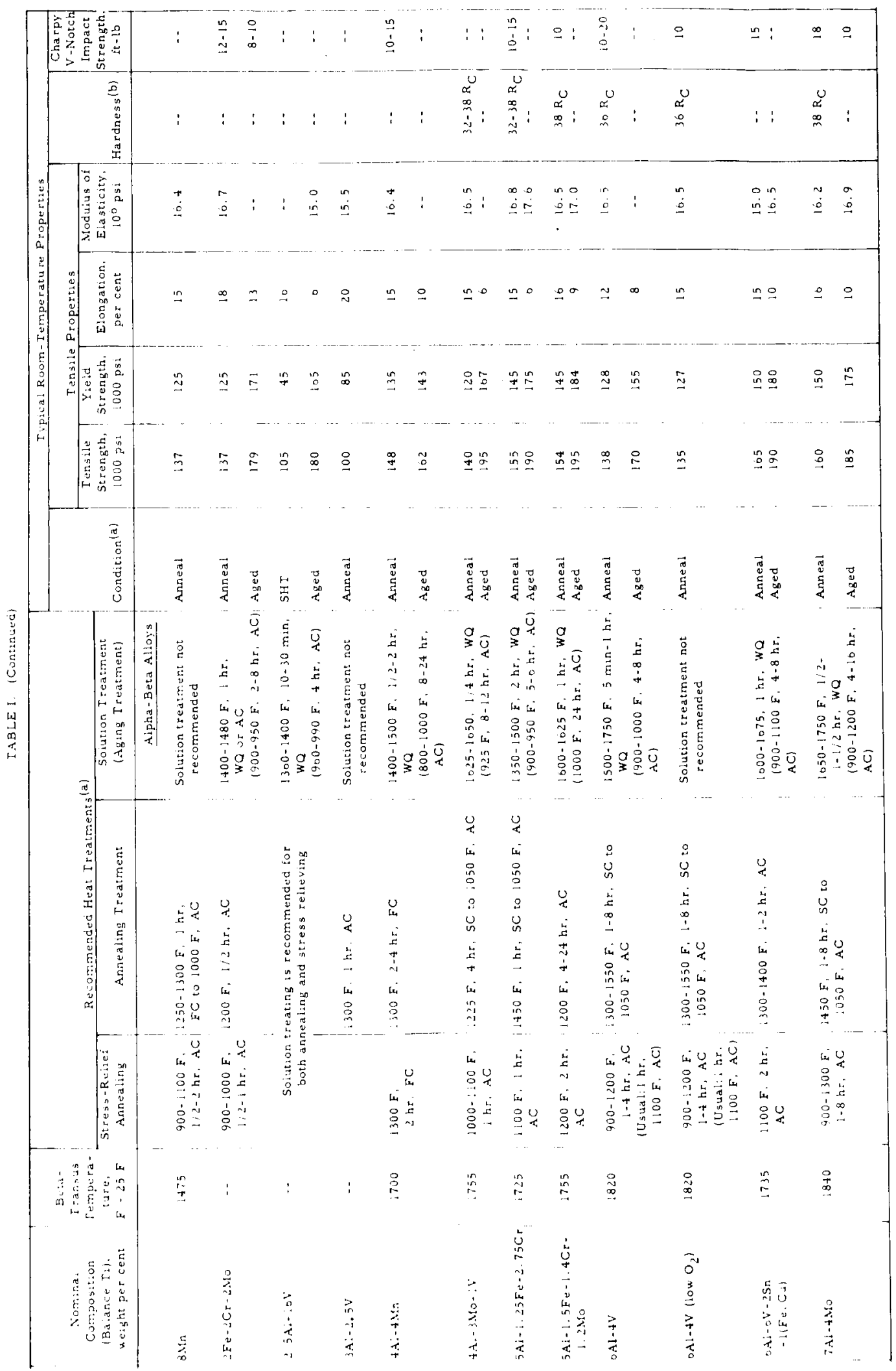




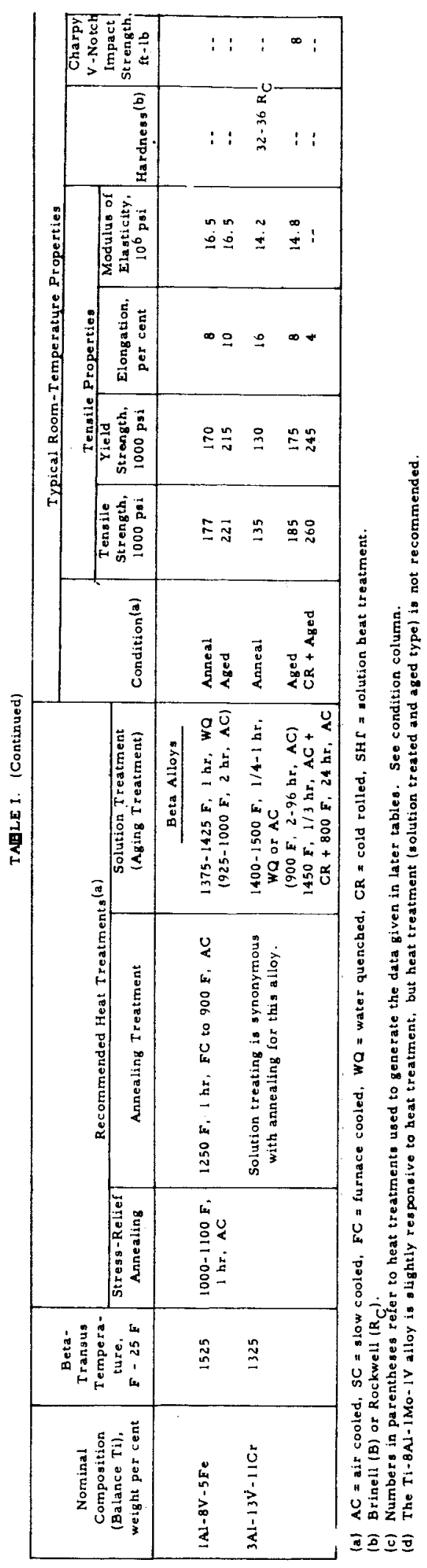


TABLE II. PRODUCER DESIGNATIONS AND FORMS AVAILABLE FOR TITANIUM AND TITANIUM ALLOYS

\begin{tabular}{|c|c|c|}
\hline $\begin{array}{l}\text { Nominal Composition } \\
\text { (Balance Ti) } \\
\text { weight per cent }\end{array}$ & Producer Designalions(a) & $\begin{array}{c}\text { Forma } \\
\text { Available(b) }\end{array}$ \\
\hline \multicolumn{3}{|c|}{ Unalloyed Grades } \\
\hline $99.5 \mathrm{Ti}$ & $\mathrm{A}-30, \mathrm{HA}-1930, \mathrm{RMI}-30, \mathrm{RD}-30, \mathrm{Ti}-35 \mathrm{~A}, \mathrm{WC}-30$ & $B, F, S, E, T, W$ \\
\hline 99. $2 \mathrm{Ti}$ & GOG-40, A-40, HA-1940, RMI-40, RD-40, Ti-55A, wC-40 & $B, F, S, E, T, W$ \\
\hline 99. $0 \mathrm{Ti}$ & GOC-55, A-55, HA-1950, RMI-55, RD-55, Ti-65A, WC-55 & $B, F, S, E, T, W$ \\
\hline $99.0 \mathrm{Ti}$ & GOC-70, A-70, HA-1970, RMI-70, RD-70, $\mathrm{ri}-75 \mathrm{~A}, \mathrm{wC}-70$ & $B, F, S, E, T, W$ \\
\hline $98.9 \mathrm{Ti}$ & OMC-105, Ti-100A & $B, F, S, E, T, W$ \\
\hline $0.15-0.20 \mathrm{Pd}$ & $\begin{array}{l}\text { A-40Pd, HA-1940Pd, OMC-103, RMI-0.2Pd, RD-015, Ti-0.15Pd } \\
\text { Alpha Alloys }\end{array}$ & $B, F, S, E, T, W$ \\
\hline $5 \mathrm{Al}-2.5 \mathrm{Sn}$ & $\begin{array}{l}\text { A-110AT, HA-5137, OMC-166A, RMI-5Al-2.5Sn, RD-110, } \\
\text { Ti-5Al-2.5Sn }\end{array}$ & B, F, S, E, W \\
\hline $5 \mathrm{Al}-2.5 \mathrm{Sn}\left(\mathrm{low} \mathrm{O}_{2}\right)$ & A-95AT, HA-5I 37ELI, RMI-5Al-2. 5Sn ELI, Ti-5Al-2. 5Sn ELI & $B, F, S, E, W$ \\
\hline $5 A l-5 S n-5 Z r$ & $T i-5 A 1-5 S n-5 Z r$ & $B, F, S, W$ \\
\hline $7 \mathrm{Al}-12 \mathrm{Zr}$ & RMI-7AI-12Zr, Ti-7Al-12Zr & $B, F, S, W$ \\
\hline $7 \mathrm{Al}-2 \mathrm{Cb}-1 \mathrm{Ta}$ & RMI-7AI-2Cb-1Ta, Ti-7Al-2Cb-1Ta & $B, F, S, W$ \\
\hline $8 \mathrm{Al}-1 \mathrm{Mo}-1 \mathrm{~V}$ & HA-8116, RMI-8A1-1Mo-1V, RD-8-1-1, Ti-8AI-1Mo-1V, WC-8-1-1 & $B, F, S, E, W$ \\
\hline 2. $25 \mathrm{Al}-11 \mathrm{Sn}-5 \mathrm{Z} \mathrm{r}-1 \mathrm{Mo}-0.2 \mathrm{Si}$ & Ti-679 (IMI-679 British) & B, F \\
\hline \multicolumn{3}{|c|}{ Alpha-Beta Alloys } \\
\hline $8 \mathrm{Mn}$ & $C-110 M, R M I-8 M n, T i-8 M n, W C-8 M n$ & $\mathrm{~B}, \mathrm{~S}$ \\
\hline $2 \mathrm{Fe}-2 \mathrm{Cr}-2 \mathrm{Mo}$ & $\mathrm{Ti}-140 \mathrm{~A}$ & $\mathrm{~B}, \mathrm{~S}$ \\
\hline 2. $5 \mathrm{Al}-16 \mathrm{~V}$ & RMI-16V-2.5AI, RD-175 & $\mathrm{B}, \mathrm{S}$ \\
\hline $3 \mathrm{Al}-2.5 \mathrm{~V}$ & $R M I-3 A I-2.5 V, R D-100$ & $\mathrm{~B}, \mathrm{~S}, \mathrm{E}, \mathrm{T}$ \\
\hline $4 \mathrm{~A} 1-4 \mathrm{Mn}$ & C-130AM, HA-4145, RMI-4Al-4Mn, RD- 130 & $\mathrm{~B}, \mathbf{F}$ \\
\hline $4 \mathrm{Al}-3 \mathrm{Mo}-1 \mathrm{~V}$ & RMI-4Al-3Mo-1V, Ti-4Al-3Mo-IV & B, $\mathbf{S}$ \\
\hline $5 \mathrm{Al}-1.25 \mathrm{Fe}-2.75 \mathrm{Cr}$ & $\mathrm{Ti}-5 \mathrm{Al}-4 \mathrm{~F} \mathrm{eCr}$ & $B, F$ \\
\hline $5 \mathrm{Al}-1.5 \mathrm{Fc}-1.4 \mathrm{Cr}-1.2 \mathrm{Mo}$ & $\mathrm{Ti}-155 \mathrm{~A}$ & B, F \\
\hline $6 \mathrm{Al}-4 \mathrm{~V}$ & $\begin{array}{l}\text { C-120AV, HA-6510, OMC-165A, RMI-6Al-4V, RD-64, } \\
\text { Ti-6Al-4V, WC-6-4 }\end{array}$ & $B, F, S, E, W$ \\
\hline $6 \mathrm{Al}-4 \mathrm{~V}\left(\mathrm{low} \mathrm{O}_{2}\right)$ & $\begin{array}{l}\text { C-120AV, HA-6510 ELI or HA-6148, OMC-164B, RMI-6A1-4V ELI, } \\
\text { Ti-6A1-4V ELI }\end{array}$ & $B, F, S, E, W$ \\
\hline $6 A 1-6 V-2 S n-1(F e, C u)$ & C-125 AVT, HA-5158, RMI-6Al-6V-2Sn, Ti-6Al-6V-2Sn, WC-6-6-2 & $B, F, S, E, W$ \\
\hline $7 \mathrm{Al}-4 \mathrm{Mo}$ & $\begin{array}{c}\text { C-135A Mo, HA-7146, RMI-7Al-4Mo, Ti-7Al-4Mo, WC-7-4 } \\
\text { Beta Alloys }\end{array}$ & $\mathbf{B}, \mathbf{F}$ \\
\hline $1 \mathrm{Al}-8 \mathrm{~V}-5 \mathrm{~F} \mathrm{C}$ & RMI- $\mid \mathrm{A} I-8 \mathrm{~V}-5 \mathrm{Fe}$ & $\mathrm{B}, \mathrm{F}$ \\
\hline $3 \mathrm{Al}-13 \mathrm{~V}-1 \mathrm{ICr}$ & $\begin{array}{l}\text { B-120VCA, RMI-13V-11Cr-3Al, RD-120, Ti-13V-11Cr-3AI, } \\
\text { WC-13-11-3 }\end{array}$ & $B, F, S, E, W$ \\
\hline
\end{tabular}

(a) A-, B-, C-: Crucible Steel Company GOC-: G. O. Carlson, Inc. HA-: Harvey Aluminum Company OMC -: Oregon Metallurgical Corporation RD-: $R$ and D Metals Company (wire supplier) RMI-: Reactive Metals, Inc.

Ti-: Titanium Metals Corp. of America (TMCA) WC-: Wah Chang Corporation (b) B - Billets and bars

$F$ - Forgings

$S$ - Plate, sheet, and strip

E - Extrusions

$T$ - Tubing

w - Wire 


\section{$\therefore$ \\ ALPHA ALLOY - Ti-5Al-2.5Sn (Ref. 4)}

Structure. The structure of Ti-5A1-2.5Sn at room temperature is essentially all alpha. Traces of $\beta$-phase can usually be detected metallographically resulting from the stabilization of this phase by iron and manganese impurities. This small amount of $\beta$-phase can be detrimental to very low temperature properties, however a low interstitial grade (ELI) which also has a lower iron and manganese content can be used for these applications. The $\alpha$-structure has two basic forms - equiaxed and acicular. The equiaxed structure is obtained by working and annealing in the $\alpha$-phase field. The $\alpha$ to $\alpha-\beta$ transus is about $1875 \mathrm{~F}$ and all $\beta$-structures exist above about $1925 \mathrm{~F}$.

The acicular form of alpha results from cooling from the $\alpha-\beta$ or $\beta$-region. All metal which was beta at the elevated temperature becomes acicular alpha during cooling. Rapid cooling produces a sharp acicular martensitic $\alpha$-structure. Slow cooling produces a large rounded acicular $\alpha$-grain structure. All metal which was not transformed to beta during the elevated-temperature exposure remains in the equiaxed $\alpha$-form.

Stress-Relief Annealing. Stress-relief annealing is normally conducted in the 1000 to $1200 \mathrm{~F}$ temperature range for $1 / 4$ to 1 hour followed by air cooling. Figure 6 shows that little relaxation takes

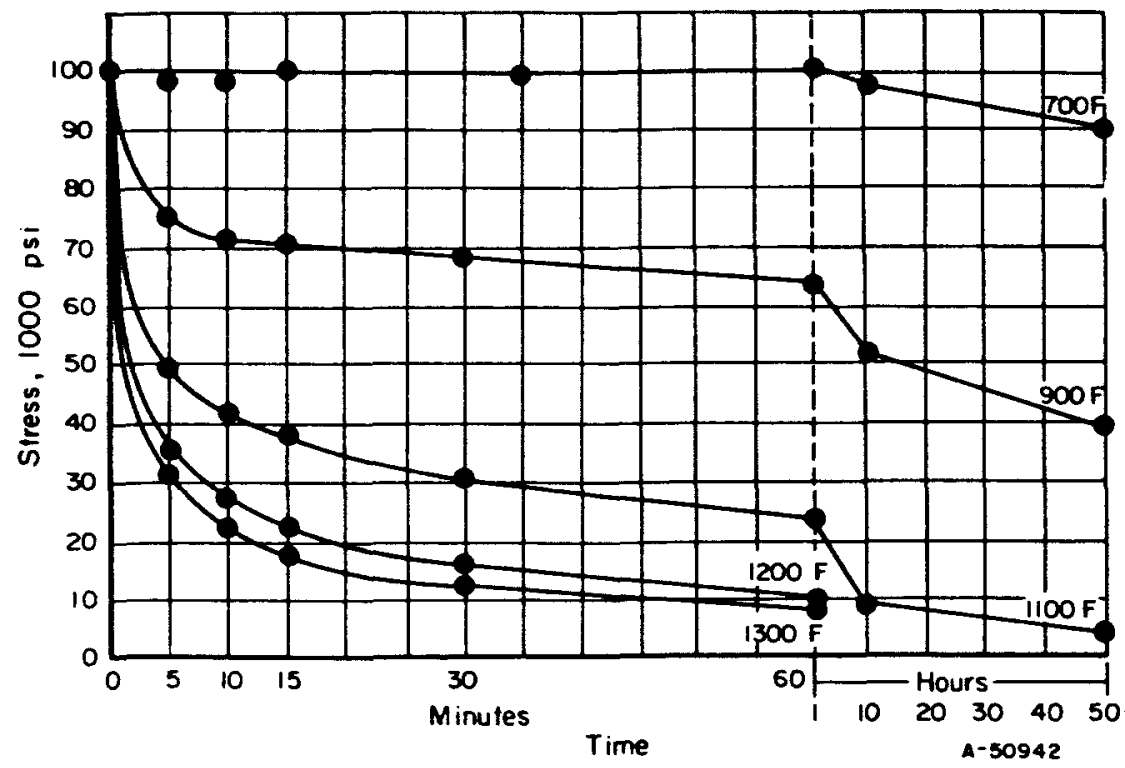

FIGURE 6. EFFECT OF TIME AND TEMPERATURE ON THE RELIEF OF RESIDUAL STRESS IN Ti-5Al-2, 5Sn (REF. 4) 
place at $700 \mathrm{~F}$, only partial relief of residual stress in practical times at $900 \mathrm{~F}$, and significant stress-relief annealing can be accomplished in 1 hour at $1100 \mathrm{~F}$.

Annealing. Ti-5Al-2.5Sn is annealed for $1 / 4$ to 4 hours in the temperature range 1300 to $1600 \mathrm{~F}$. The shorter exposure times are used with the higher temperatures. Temperatures above $1600 \mathrm{~F}$ are not used because of excessive oxidation and grain growth. Cooling rate has little effect on properties and material is normally air cooled although furnace cooling may be used in vacuum annealing (this annealing treatment restores best ductility and toughness to the alloy).

Heating into the $\beta$-field without subsequent working in the $\alpha$-field causes lower ductility at room temperature with little effect on tensile-strength properties (Table III). Toughness can be increased by $\beta$-heat treatment.

TABLE III. TENSILE PROPERTIES OF ANNEALED Ti-5A1-2. 5Sn EXTRUDED AT $1700 \mathrm{~F}$ (a) (REF. 4)

\begin{tabular}{|lcccc|}
\hline Annealing Treatment & $\begin{array}{c}\text { Tensile } \\
\text { Strength, } \\
1000 \mathrm{psi}\end{array}$ & $\begin{array}{c}\text { Yield } \\
\text { Strength, } \\
1000 \mathrm{psi}\end{array}$ & $\begin{array}{c}\text { Elongation, } \\
\% \text { in }\end{array}$ & $\begin{array}{c}\text { Reduction } \\
\text { of Area, } \\
\%\end{array}$ \\
\hline $2100 \mathrm{~F}$, water quench & 153.1 & 152.6 & 12.5 & 25.0 \\
$2100 \mathrm{~F}$, air cool & 149.0 & 138.8 & 8.3 & 15.2 \\
$2100 \mathrm{~F}$, furnace cool & 151.8 & 141.2 & 7.5 & 13.9 \\
$1850 \mathrm{~F}$, water quench & 146.3 & 131.4 & 16.7 & 50.0 \\
$1850 \mathrm{~F}$, air cool & 143.5 & 139.0 & 16.7 & 45.7 \\
$1850 \mathrm{~F}$, furnace cool & 144.2 & 141.2 & 15.5 & 43.7 \\
$1600 \mathrm{~F}$, air cool & 138.4 & 131.8 & 16.7 & 50.3 \\
$1200 \mathrm{~F}$, air cool & 146.0 & 143.2 & 16.7 & 43.4 \\
\hline
\end{tabular}

(a) $\alpha-\beta$ extruded.

Strengthening Heat Treatments. Since Ti-5Al-2. 5Sn is essentially an all $\alpha$-alloy, heat treatment has little or no effect on mechanical properties. 
Thermal Stability. Ti-5Al-2.5Sn is metallurgically stable ùnder any conditions of stress, temperature, and time up to the annealing temperature.

$$
\text { ALPHA-BETA ALLOY - Ti-6Al-4V (REF. 4) }
$$

Structure. Ti-6Al-4V is an $\alpha-\beta$ alloy in which an $\alpha$-stabilizer, aluminum, and a $\beta$-stabilizer, vanadium, are combined. The response of this alloy to thermal treatment can best be discussed in terms of the phase relationships. Figure 7 shows a schematic vertical section of the ternary phase diagram.

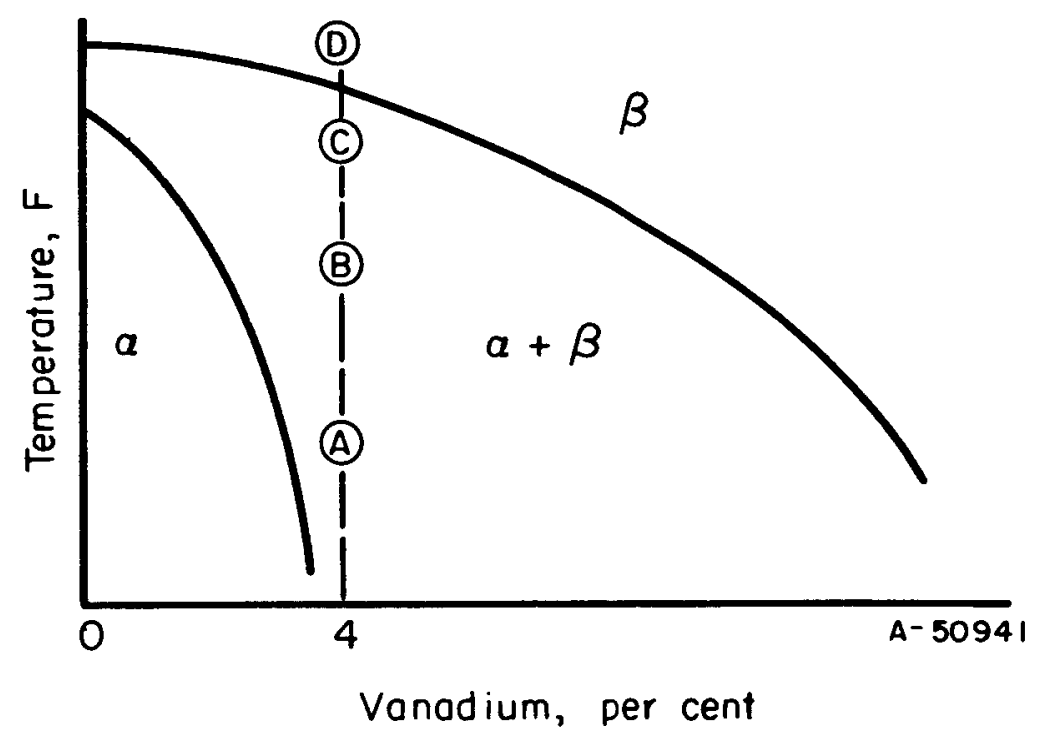

FIGURE 7. THE PHASE RELATIONSHIPS FOR Ti-6AI-4V (REF. 4)

Annealing temperatures, indicated by Point $\mathrm{A}$, usually are in the range from 1200 to $1400 \mathrm{~F}$. The resulting structure is mainly $\alpha$-phase, with beta retained in the grain boundaries. This high proportion of alpha is a result of the relatively high solubility of vanadium in alpha, and the presence of aluminum, an $\alpha$-stabilizer. By solution annealing and quenching from temperatures higher in the $\alpha-\beta$ field (Points $B$ to $C$ ), the alloy can be strengthened by subsequent aging. This increase in heat-treatment response is caused both by the increased amount of $\beta$-phase in the structure and the change in alloy content of the $\beta$-phase with increasing temperature. As the solution-annealing temperature is increased, the vanadium content of the equilibrium $\beta$-phase eventually is lowered below the limit at which $\beta$-phase is retained on quenching; the beta transforms partially to alpha prime (martensite) after solution annealing at about $1750 \mathrm{~F}$, whereas at 
$1550 \mathrm{~F}$, beta is retained. At the latter solution-annealing tempera- . ture, however, the $\beta$-phase is mechanically unstable after quenching, and martensite can then be formed during plastic straining. This condition is characterized by a low ratio of yield to ultimate tensile strengths. Maximum heat treatment response is attainable after solution annealing in the $\beta$-field (D); however, the strength increase is offset by a considerable loss of ductility ensuing from the transformed structure, so that solution anneals usually are not carried out in the all-beta range but rather from intermediate to high in the $\alpha-\beta$ range (Points $B$ to $C$ ).

The interstitial elements carbon, oxygen, and nitrogen increase the $\beta$-transus with increasing concentration. When these elements are in excess of the normal levels, the $\beta$ to $\alpha$-reaction is accelerated by the presence of these elements dissolved in the $\beta$-phase. At normal concentrations most of the interstitials are dissolved preferentially in the $\alpha$-phase so that in practice little effect is observed on the transformation kinetics.

Stress-Relief Annealing. Temperatures of 1000 to $1200 \mathrm{~F}$ for periods of $1 / 2$ to l hour, followed by air cooling, are commonly used to stress relieve $\mathrm{Ti}-6 \mathrm{Al}-4 \mathrm{~V}$. To minimize oxidation, the time and temperatures should be as low as possible. Data covering the effect of time and temperature on residual stress are illustrated in Figure 8 .

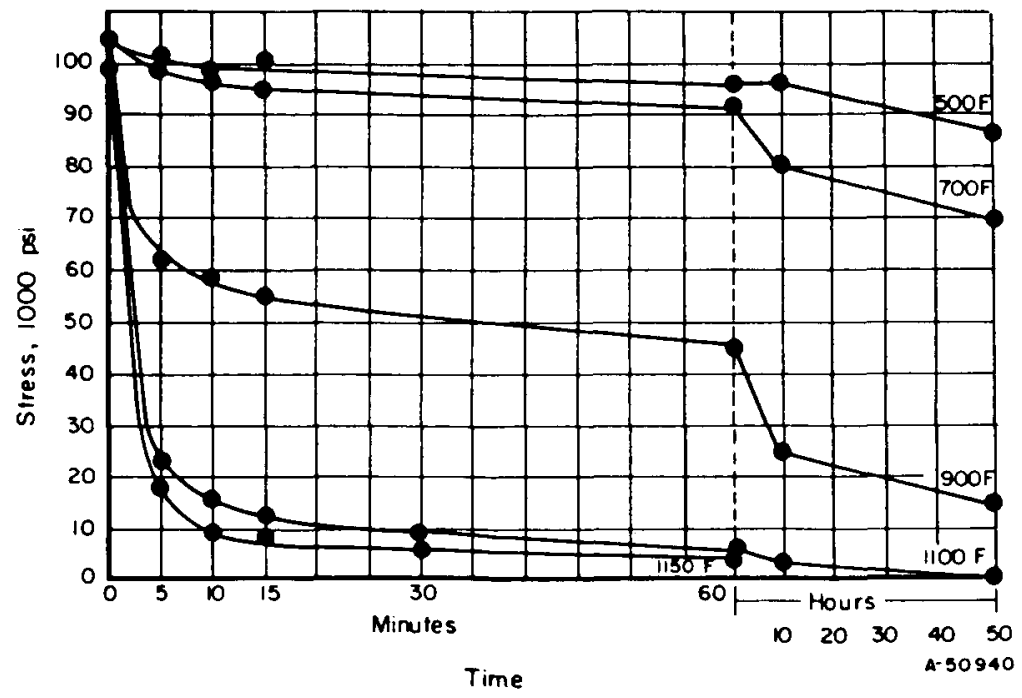

FIGURE 8. EFFECT OF TIME AND TEMPERATURE ON THE RELIEF OF RESIDUAL STRESS IN Ti-6Al-4V (REF. 4) 
Annealing. Annealing heat treatments usually involve holding for 1 to 2 hours at 1300 to $1500 \mathrm{~F}$, furnace cooling to about $1100 \mathrm{~F}$, and then air cooling to room temperature. Time, temperature, and cooling rate are selected so that the annealing treatment achieves a mixed $\alpha-\beta$ structure that is ductile and stable. The majority of $\mathrm{Ti}-6 \mathrm{Al}-4 \mathrm{~V}$ product is supplied in the annealed condition.

Strengthening Heat Treatments. Generally the best heattreated properties are developed by solution annealing at 1550 to $1750 \mathrm{~F}$, water quenching, and aging at temperatures from 900 to $1100 \mathrm{~F}$.

Hardenability. Heat-treatable titanium alloys, such as $\mathrm{Ti}-6 \mathrm{Al}-4 \mathrm{~V}$, show a rather shallow hardenability. This is due to the low thermal conductivity of titanium alloys which allows transformation of the $\beta$-phase to omega or alpha during cooling from the solution-annealing temperature (Figure 9). Data shown in Figures 10 and 11 indicate that full strength in $\mathrm{Ti}-6 \mathrm{Al}-4 \mathrm{~V}$ alloy sections over about 1 inch in thickness is not expected.

Solution Annealing. Solution annealing Ti-6Al-4V at about $1550 \mathrm{~F}$ results in maximum ductility and best formability. Solution annealing at 1700 to $1750 \mathrm{~F}$ develops maximum strength properties (Figure 12).

The solution temperature is effectively lowered when the workpiece is not immediately quenched. The effect of time delay before quenching on the tensile properties of Ti-6Al-4V is shown in Figure 13.

Aging Heat Treatments. The strength of $\mathrm{Ti}-6 \mathrm{Al}-4 \mathrm{~V}$ is improved through aging in the temperature range 900 to $1100 \mathrm{~F}$ for 1 to 24 hours. Aging heat treatments must be preceded by solution annealing. Higher aging temperatures result in overaging and a considerable loss in strength and only a slight improvement in ductility. Figure 14 shows the effect of aging time at $900 \mathrm{~F}$ on the tensile properties of $\mathrm{Ti}-6 \mathrm{Al}-4 \mathrm{~V}$ material solution treated at $1550 \mathrm{~F}$. Aging times in excess of 8 hours have little effect on properties. 


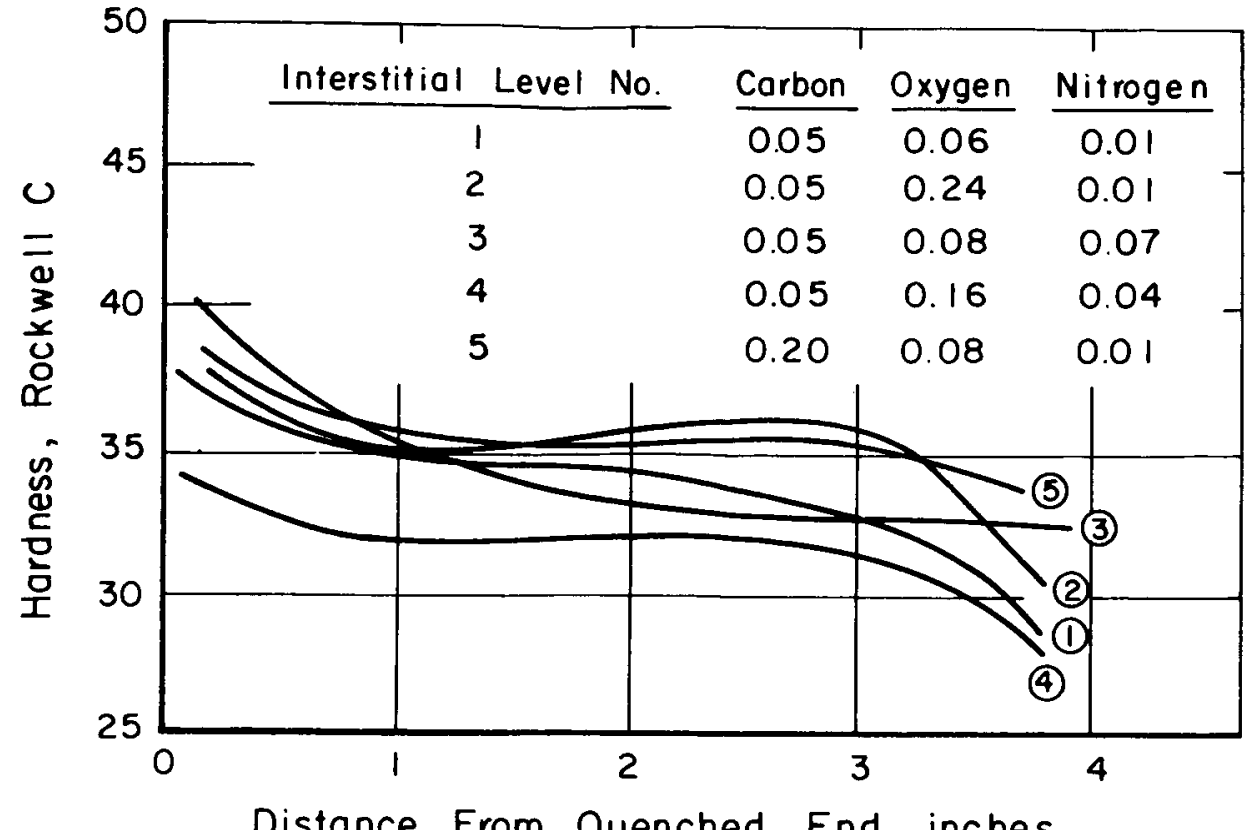

A- 50939

FIGURE 9. END-QUENCH HARDENABILITY CURVES FOR Ti-GAI-4V (REF. 4) Solution temperatures were $100 \mathrm{~F}$ above the beta transus.

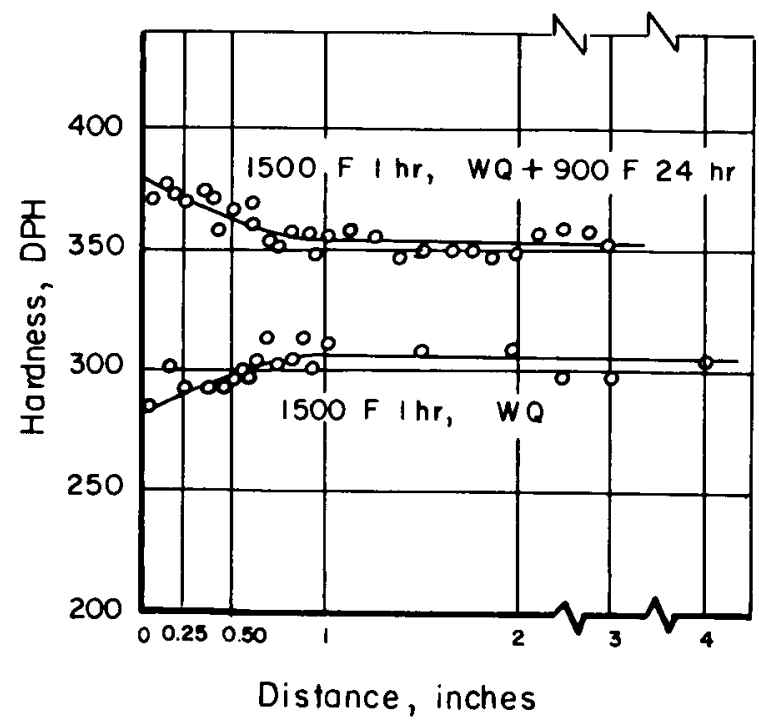

FIGURE 10. THE EFFECT OF AGING ON HARD NESS OF A Ti-6Al-4V SPECIMEN END QUENCHED FROM 1550 F (REF. 4)

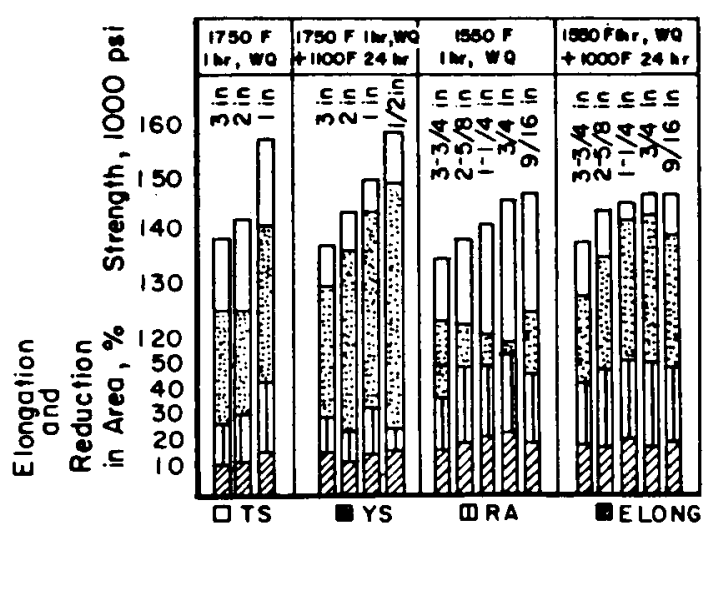

FIGURE 11. THE EFFECT OF SECTION SIZE ON THE TENSILE PROPERTIES OF Ti-6Al-4V (REF. 4) 


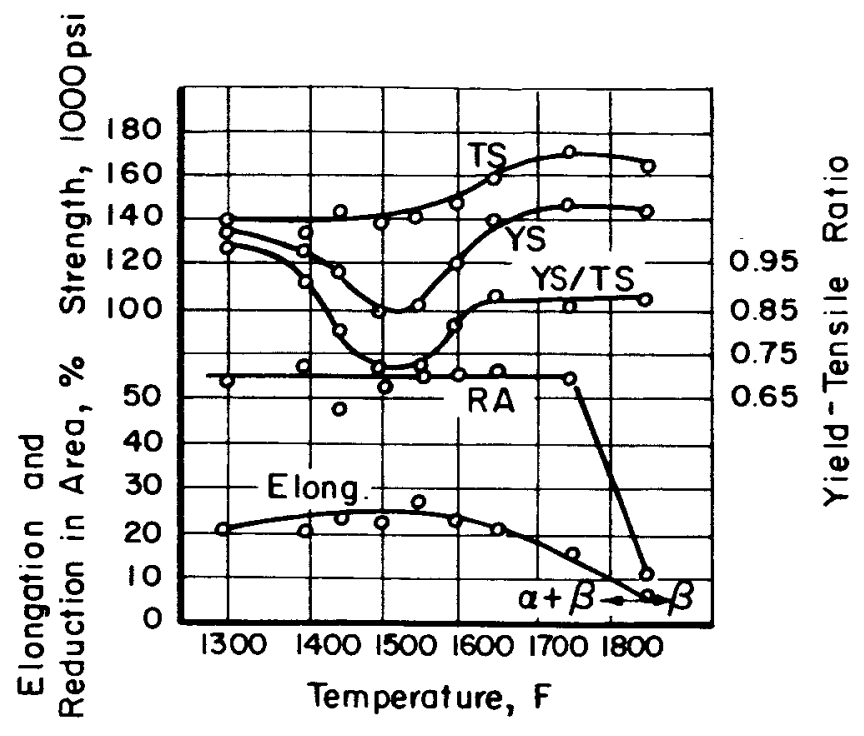

FIGURE 12. THE EFFECT OF SOLUTION TEMPERATURE ON TENSILE PROPERTIES OF Ti-6Al-4V (REF. 4)
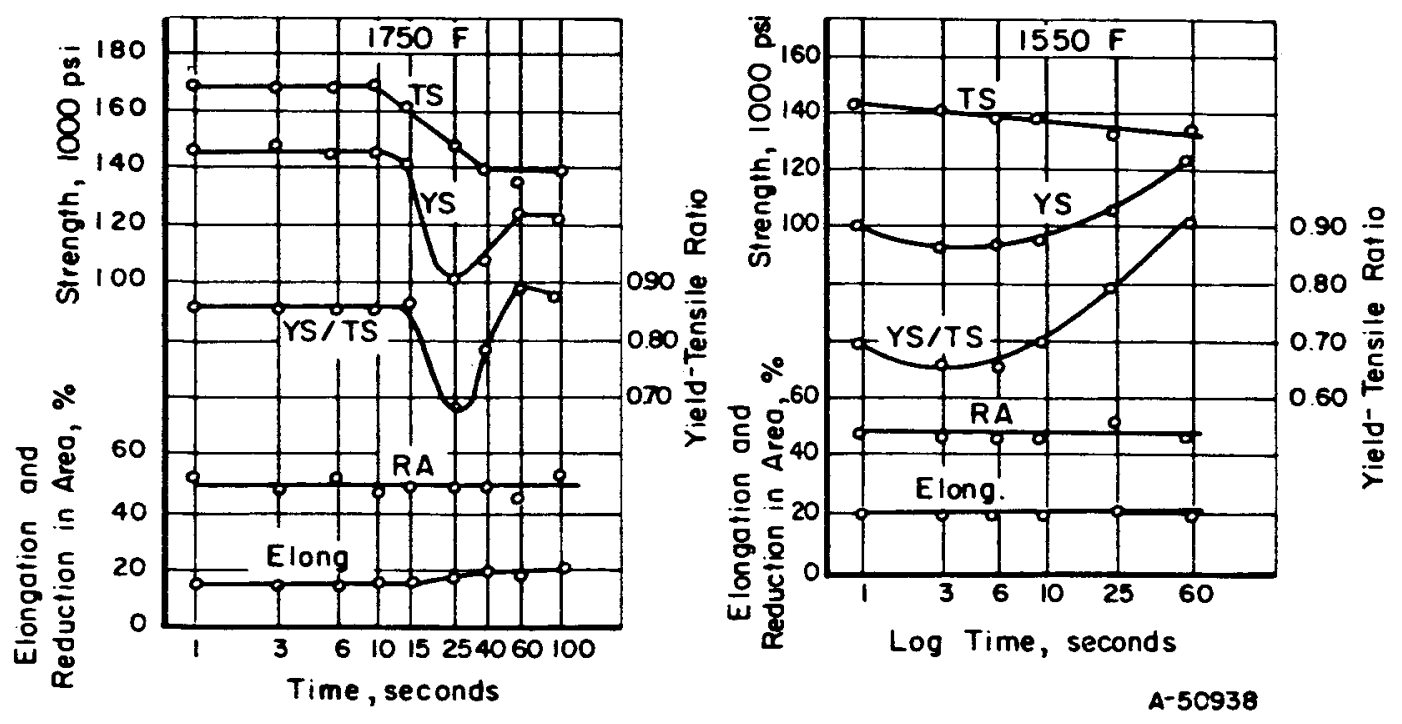

FIGURE 13. THE EFFECT OF DELAYED WATER QUENCHING FROM 1750 AND $1550 \mathrm{~F}$ ON THE TENSILE PROPERTIES OF Ti-6Al-4V (REF. 4) 


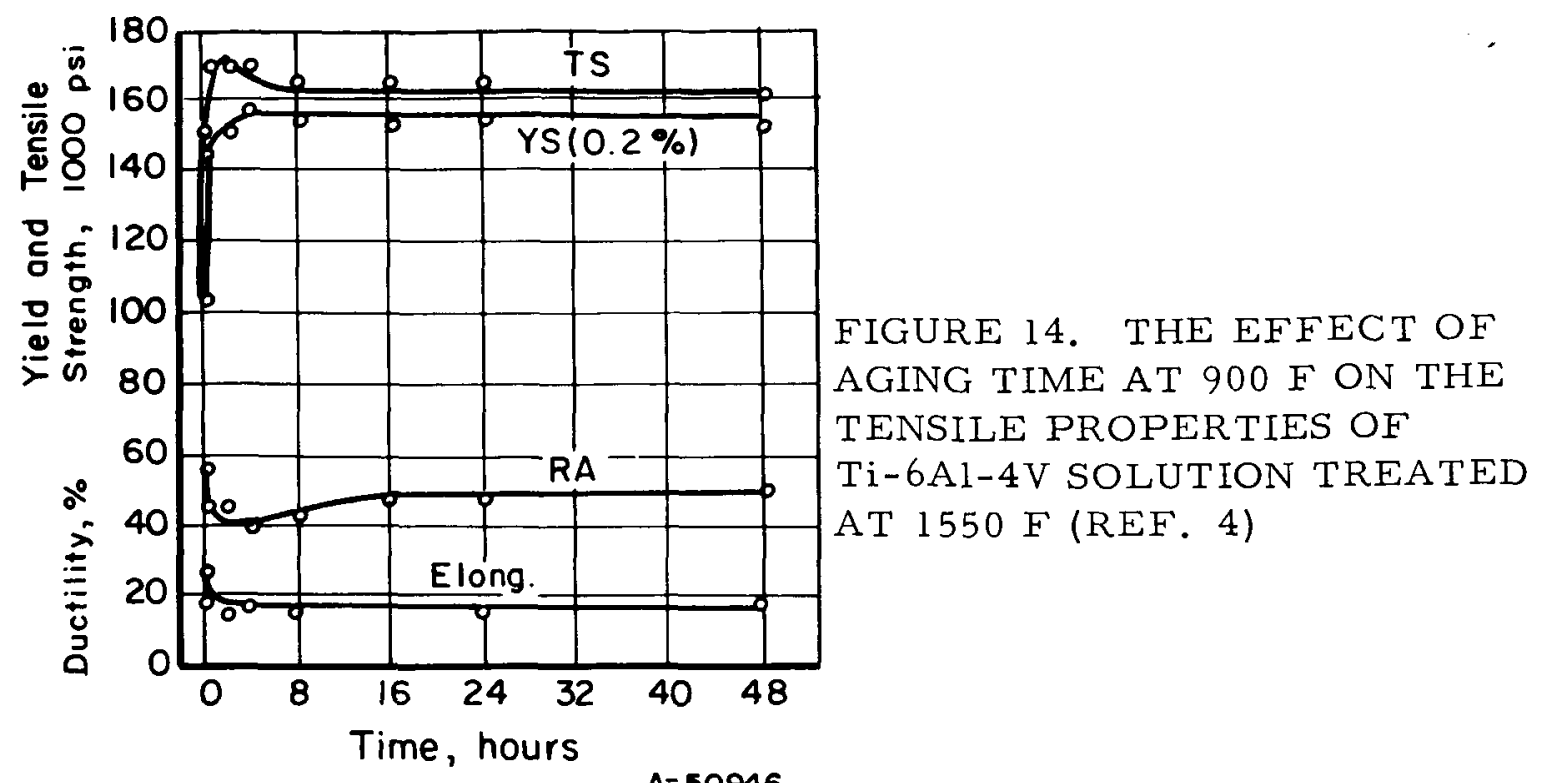

Thermal Stability. In general, $\mathrm{Ti}-6 \mathrm{Al}-4 \mathrm{~V}$, as annealed or as aged under ordinary service conditions, is considered stable. The alloy has the ability to retain the original mechanical properties after prolonged thermal exposure in a variety of environments. Elevatedtemperature exposure of solution-treated material, during operations such as forming, may lead to strength increases and a corresponding decrease in ductility. In such cases the alloy should be stabilized by aging or annealing prior to service.

BETA ALLOY - Ti-13V-11Cr-3Al (REF. 4)

Structure. The Ti-13V-llCr-3Al structure is entirely beta at room temperature after annealing from above the $\beta$-transus. The structure is easily obtained even with slow cooling rates because of the $\beta$-stabilizing characteristics of the high vanadium and chromium content of the alloy.

The effect of variable chromium content on the phase relationships of Ti-13V-11Cr-3Al is shown in Figure 15 . The alloy is hypoeutectoidal with a $\beta$-transus between 1200 and $1300 \mathrm{~F}$. The high vanadium content contributes to the stabilization of the $\beta$-phase to this low temperature.

Figure 16 shows the effect of variable aluminum content. Increasing aluminum content stabilizes the $\alpha$-phase, which in turn 
raises the $\beta$-transus temperature. Oxygen also raises the $\beta$-transus temperature. Without the minor aluminum addition the $\beta$-transus temperature would be lowered by about $200 \mathrm{~F}$.

The $\beta$-phase is thermodynamically stable down to about $1200 \mathrm{~F}$ (with low oxygen content), however, the decomposition of the $\beta$-phase is very sluggish even at lower temperatures. This is illustrated in Figure 17. In addition to the decomposition products of the $\beta$-phase, alpha and $\mathrm{TiCr}_{2}$, and $\omega$-phase is believed to be formed. The exact conditions for the development of omega have not been established. It is believed that omega is unstable and will decompose rapidly above $1000 \mathrm{~F}$.

Stress-Relief Annealing. Stress-relief annealing of Ti-13V$11 \mathrm{Cr}-3 \mathrm{~A}$ is normally carried out by annealing for $1 / 4$ to 4 hours at 900 to $1200 \mathrm{~F}$. The shorter times are used with the higher temperatures.

Annealing. Normal cooling from the annealing temperature retains the $\beta$-phase structure. Thus, annealing treatments for $\mathrm{Ti}-13 \mathrm{~V}-11 \mathrm{Cr}-3 \mathrm{Al}$ are the same as solution treating.

Strengthening Heat Treatments. High strengths are developed in Ti-13V-11Cr-3Al by solution annealing above $1400 \mathrm{~F}$, water quenching or air cooling, and aging at 800 to $1000 \mathrm{~F}$. The Ti-13V$11 \mathrm{Cr}-3 \mathrm{Al}$ also may be strengthened by cold working which is illustrated later.

Hardenability. Thick sections of Ti-13V-11Cr-3Al can be hardened by aging solution-annealed material. This result is obtainable due to the sluggishness of the $\beta$-phase which is retained even in the center of very thick sections and is subsequently age hardenable.

Solution Annealing. Within the solution-annealing range of about 1300 to $1900 \mathrm{~F}$ there is little change in the hardness (Figure 18) of annealed or subsequent aged material with temperature. Cooling rate seems to have essentially no effect due to the high $\beta$-stabilizer content of the alloy. However, long solution-annealing periods at high temperatures lower the ductility in aged material through excessive grain growth and breakdown of favorable nucleation site distribution. 


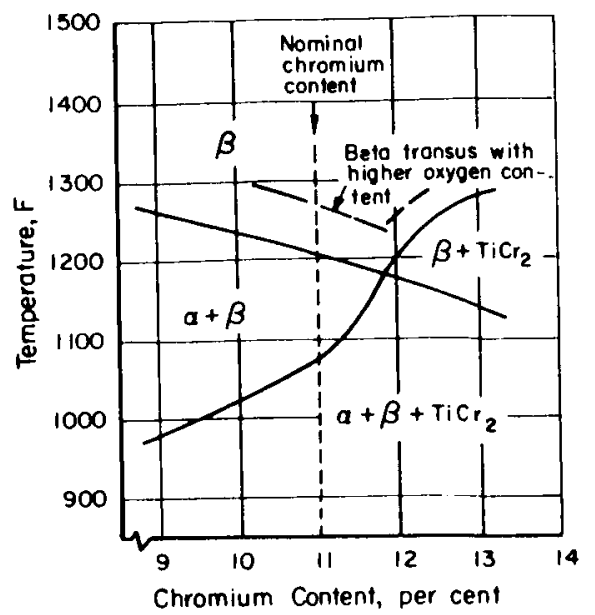

FIGURE 15. PHASE DIAGRAM OF BETA ALLOY WITH VARIABLE CHROMIUM CONTENT (Ti-13V-Cr-3Al-0.05 O 2 ) (REF. 4)

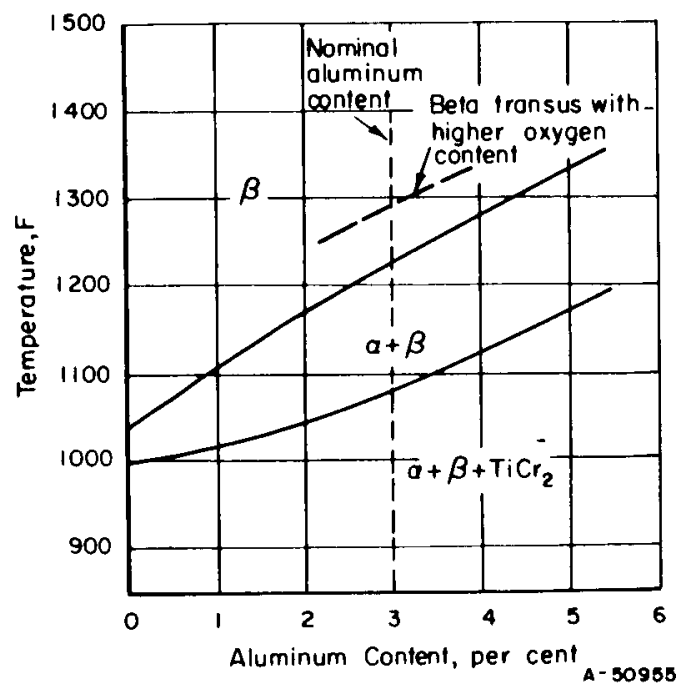

FIGURE 16. PHASE DIAGRAM OF BETA ALLOY WITH VARIABLE ALUMINUM CONTENT (Ti-13V-11Cr-A1-0.5 O $)$ (REF. 4)

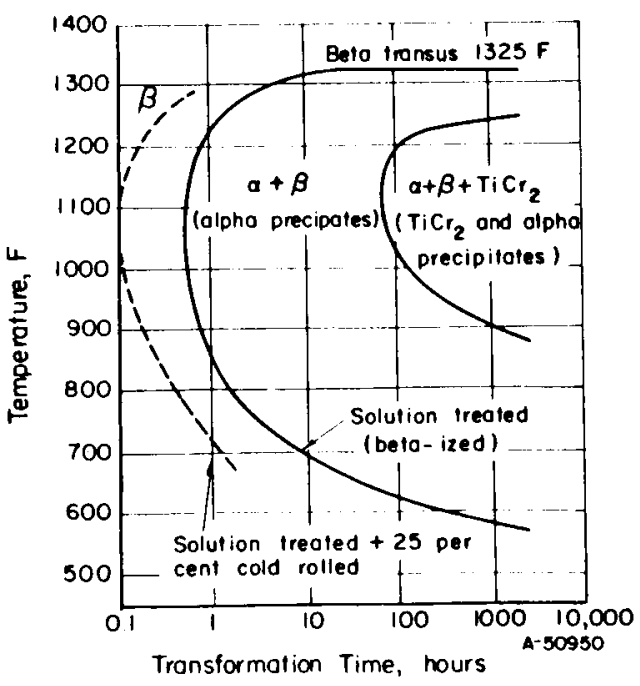

FIGURE 17. TTT DIAGRAM FOR Ti-13V-11Cr3A1-0.15 $\mathrm{O}_{2}$ AS DETERMINED BY METALLOGRAPHIC TECHNIQUES (REF. 4) 


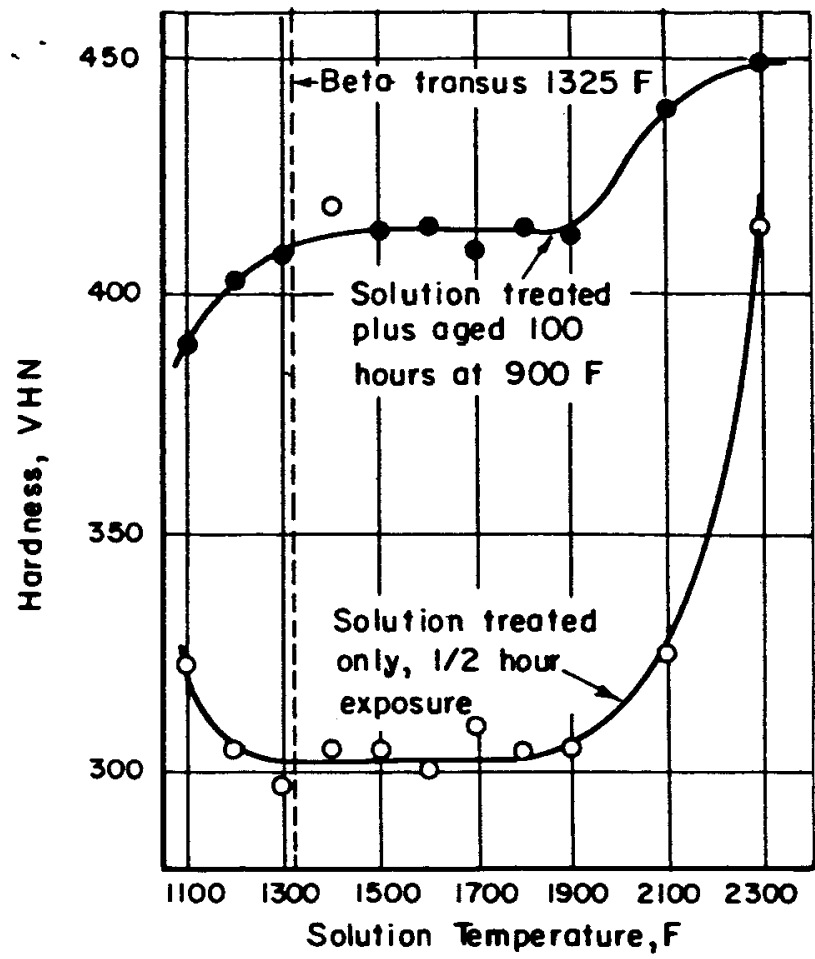

FIGURE 18. EFFECT OF SOLUTION TEMPERATURE ON THE ANNEALED AND ANNEALED-PLUS AGED HARDNESS OF $\mathrm{Ti}-13 \mathrm{~V}-11 \mathrm{Cr}-$ $3 \mathrm{Al}$ (REF. 4)

Aging Heat Treatments. Aging Ti-13V-11Cr-3Al increases strength properties through the modification of the metastable-beta structure to $\beta$-plus-decomposition products. Decomposition of metastable-beta phase does not occur below about $600 \mathrm{~F}$. Normal aging of solution-annealed material is conducted at 800 to $950 \mathrm{~F}$ for relatively long periods of time, 20 to 100 hours. Overaging does not occur for up to 500 hours at $1000 \mathrm{~F}$ and it appears that maximum aging response occurs at about $900 \mathrm{~F}$. The aging reaction is accelerated in cold-or warm-worked material. A significantly higher strength level can be achieved by cold working the alloy between the solution heat treatment and the aging treatment.

Thermal Stability. The ability of the solution-annealed $\beta$-alloy to maintain mechanical properties is limited to relatively short exposure time at temperatures to about $600 \mathrm{~F}$. Figure 19 illustrates the effect of time on the $600 \mathrm{~F}$ stability of annealed and cold worked Ti-13V-l1Cr-3Al. The thermal stability of aged material is better than that of annealed material. However, the temperature limit for alloy stability remains in the range 575 to $600 \mathrm{~F}$ for long-time exposure. 


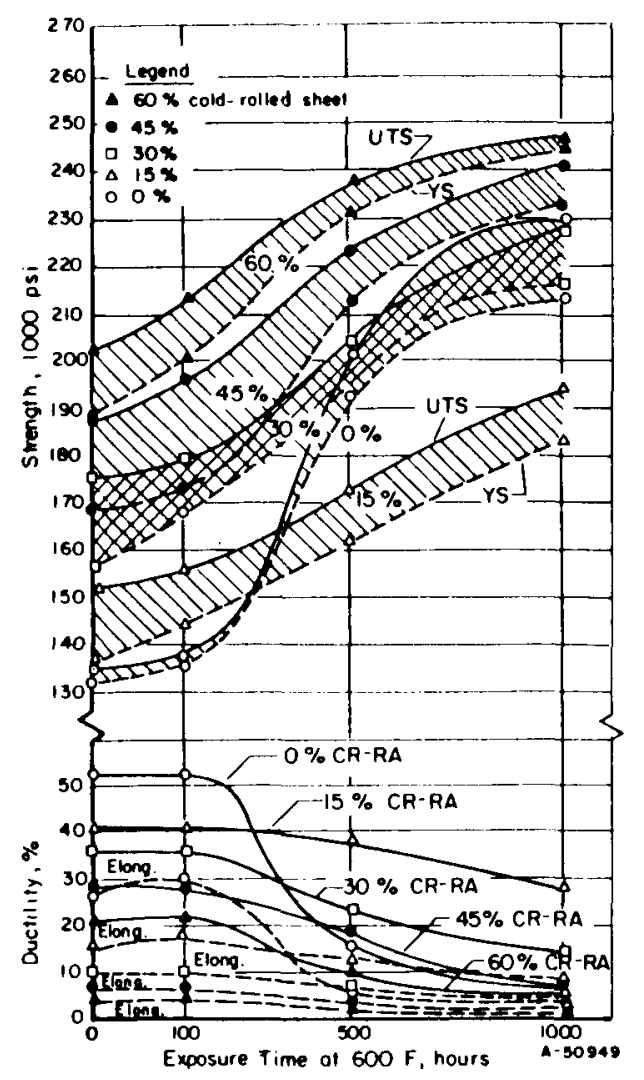

FIGURE 19. EFFECT OF THERMAL EXPOSURE AT $600 \mathrm{~F}$ ON THE TENSILE PROPERTIES OF ANNEALED-AND-WORKED $\mathrm{Ti}-13 \mathrm{~V}-11 \mathrm{Cr}-3 \mathrm{~A} 1$ (REF. 4)

TITANIUM HEAT-TREATMENT PRACTICE

Stress relieving titanium alloys relaxes residual stresses and improves ductility and toughness. Heating titanium alloys higher into the recrystallization-temperature range followed by air or furnace cooling (depending on composition) develops the maximum ductility and toughness. For strengthening purposes, titanium alloys are first solution treated at relatively high temperatures, water quenched, and finally aged at some intermediate temperature. Thus, the reasons for the heat treating of titanium and the metallurgical phenomena that heat treatments bring about are similar in principle to those employed in other metal-alloy systems. However, since titanium reacts with most atmospheres under normal heat-treating conditions, consideration of contamination effects and their control is of utmost importance. This section of the report deals with contamination, furnacing, and, finally, a discussion of techniques now being employed for the thermal treatment of titanium materials.

\section{CONTAMINATION}

Titanium is chemically very active at elevated temperatures and reacts with almost all elements including those which are most 
readily available - carbon, oxygen, nitrogen, and hydrogen. Titanium reacts with, and is contaminated by, most gaseous compounds, including $\mathrm{CO}, \mathrm{CO}_{2}, \mathrm{H}_{2} \mathrm{O}$ vapor, $\mathrm{NH}_{4}$, and many volatile organic materials. The results of such gas reactions are more serious for titanium than for many other metals, since the gaseous elements not only form compounds at the surface, but also penetrate the metal lattice causing loss of ductility and toughness. Furthermore, with the exception of hydrogen, the contaminating gases cannot be removed by vacuum heat treatment, since the reactions are irreversible.

Effect on Properties (Ref. 10) Small quantities of the interstitial elements remain in titanium after the various metal-winning processes and additional quantities are picked up during primary and secondary fabrication processes. Heavy concentrations of carbon, oxygen, and nitrogen in the metal surface, picked up during fabrication and/or heat-treatment operations, harden and strengthen titanium. Both nitrogen and oxygen are used to surface harden titanium for increasing wear resistance in friction applications. Carbon is effective as a strengthener only up to its limit of solubility in alpha. Although hydrogen has a strengthening effect in titanium alloys, the effect is almost nil in unalloyed titanium. Ductility and toughness decrease with increasing amounts of interstitial content in unalloyed titanium. Summary curves showing the interstitial effects on titanium strength, ductility, and hardness are given in Figures 20 and 21 .

The most deleterious effect of the interstitials on the properties of unalloyed titanium is on toughness. High-purity titanium is very tough to quite low temperatures, but the presence of interstitials lowers toughness progressively with increasing interstitial content until transition-type behavior occurs (Figure 22). A tendency toward transition type of behavior occurs at 0.24 per cent oxygen equivalent, and definite transition behavior occurs at 0.36 per cent oxygen equivalent. The effects of combinations of interstitials on toughness appear to be additive on the same basis as their effects on strength, that is $3 \mathrm{C}=20=1 \mathrm{~N}$. Oxygen equivalent concentrations of carbon or nitrogen may be calculated using this relationship. 


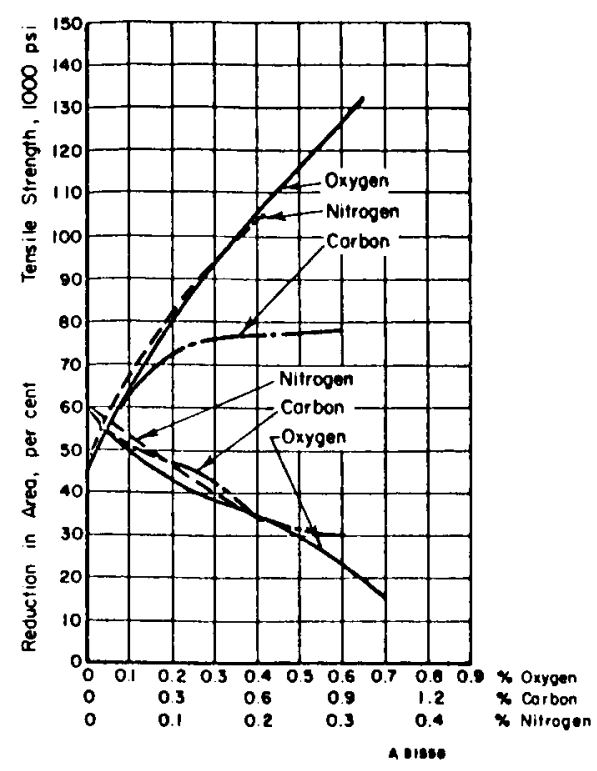

FIGURE 20. EFFECT OF CARBON, OXYGEN, AND NITROGEN ON TENSILE PROPERTIES OF IODIDE TITANIUM (REF. 10)

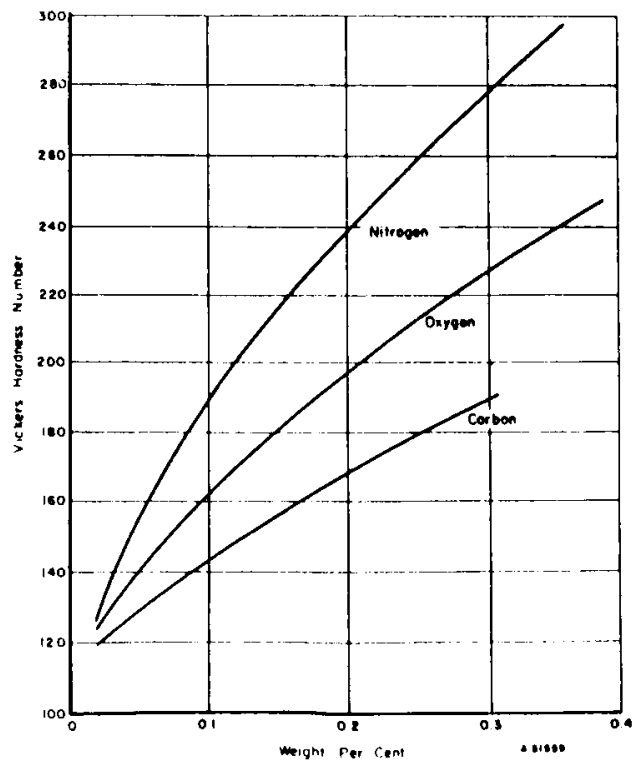

FIGURE 21. EFFECT OF CARBON, OXYGEN, AND NITROGEN ON VICKERS HARDNESS OF IODIDE TITANIUM (REF. 10) 


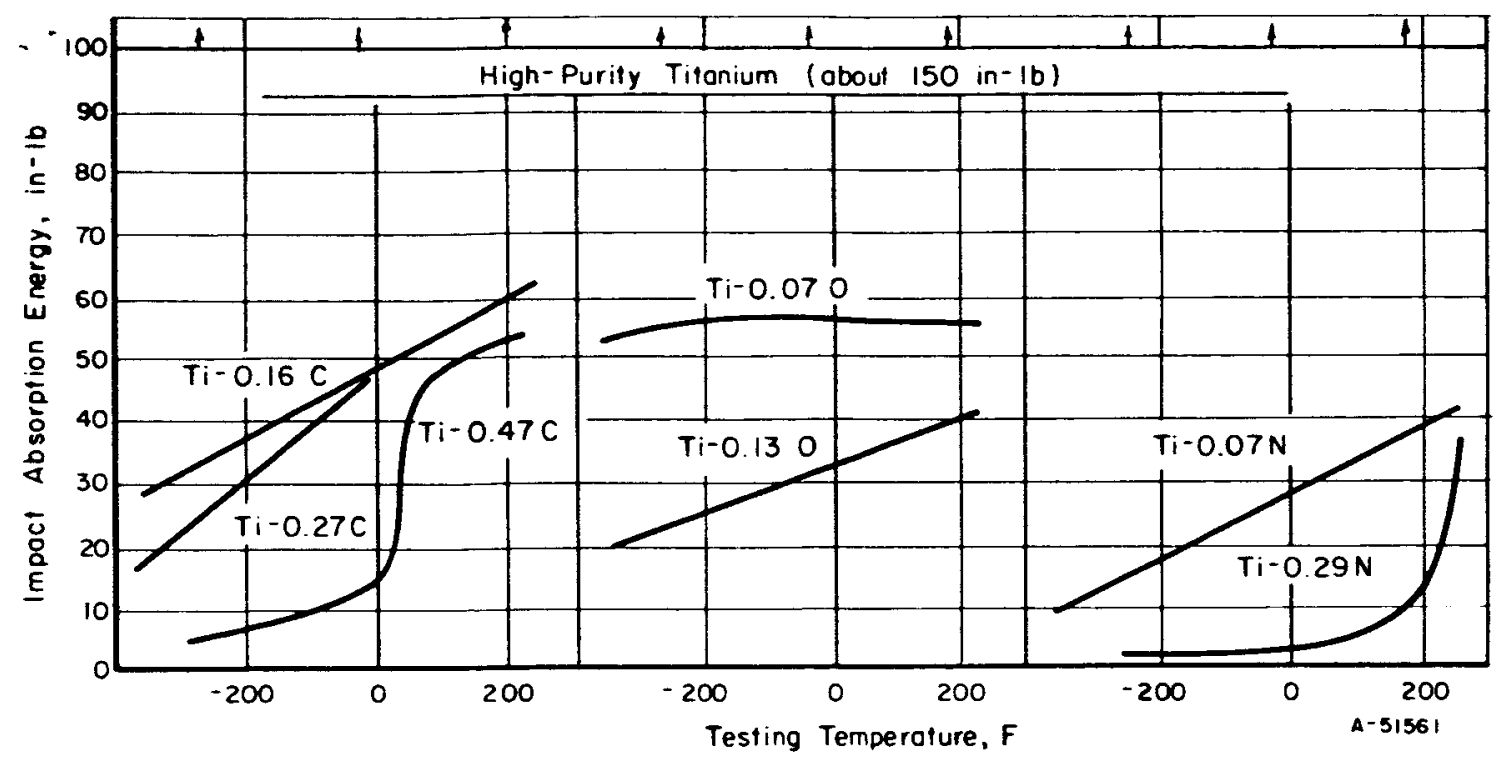

FIGURE 22. EFFECT OF INTERSTITIALS ON TOUGHNESS OF IODIDE TITANIUM (REF. 10)

Hydrogen has a similar effect upon the toughness of titanium, although at much lower concentration than that observed for carbon, oxygen, or nitrogen. Four interrelated variables have been found to affect the tendency toward embrittlement: hydrogen content, strain rate, stress concentration, and temperature. Typical effects are shown in Figure 23. From these plots, it can be seen that transition temperature is increased (i.e., embrittlement becomes more severe) as hydrogen content is increased, loading rate is increased, or notches are introduced into the samples. As might be expected, the effects are magnified in the presence of the other interstitial elements.

The effects of interstitial content on the mechanical properties of titanium alloys are much the same as for unalloyed titanium. In general, strength is increased while ductility and toughness are decreased in the presence of interstitials. However, with regard to embrittlement effects and especially embrittlement effects promoted by hydrogen, certain alloys of titanium can tolerate more interstitials than others and the embrittlement phenomenon occurs at different temperatures for the different alloys. (Ref. 10)

Oxidation (Ref. 11). Titanium is noted for its excellent resistance to many corrosive environments. This resistance tocorrosion is related to the thin, natural oxide film that forms on titanium. This oxide film does not grow significantly thicker at ambient temperatures 

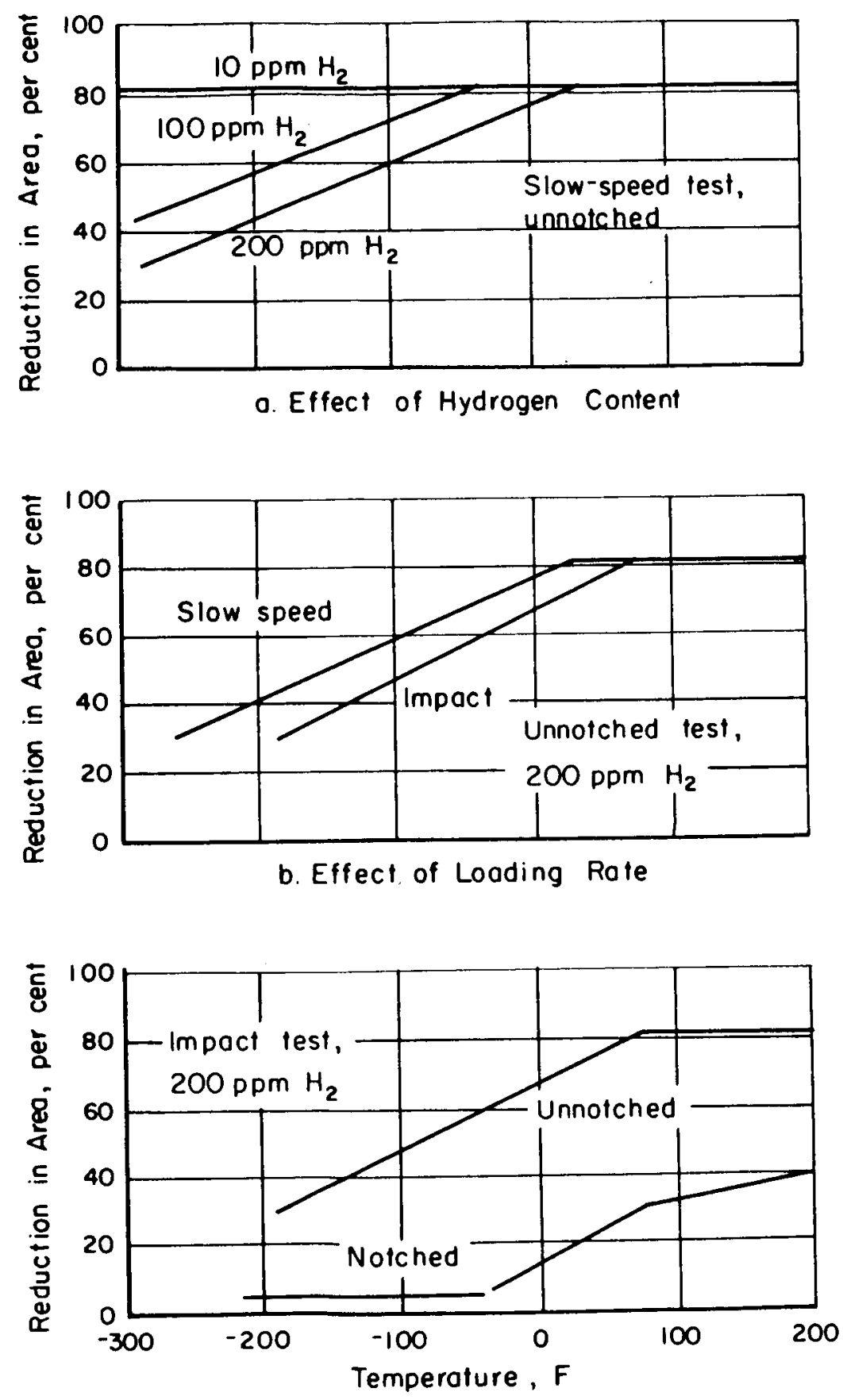

c. Effect of Stress Concentration

FIGURE 23. CHARACTERISTICS OF HYDROGEN EMBRITTLEMENT IN ALPHA ALLOYS, FROM DATA ON IODIDE TITANIUM (REF, 10) 


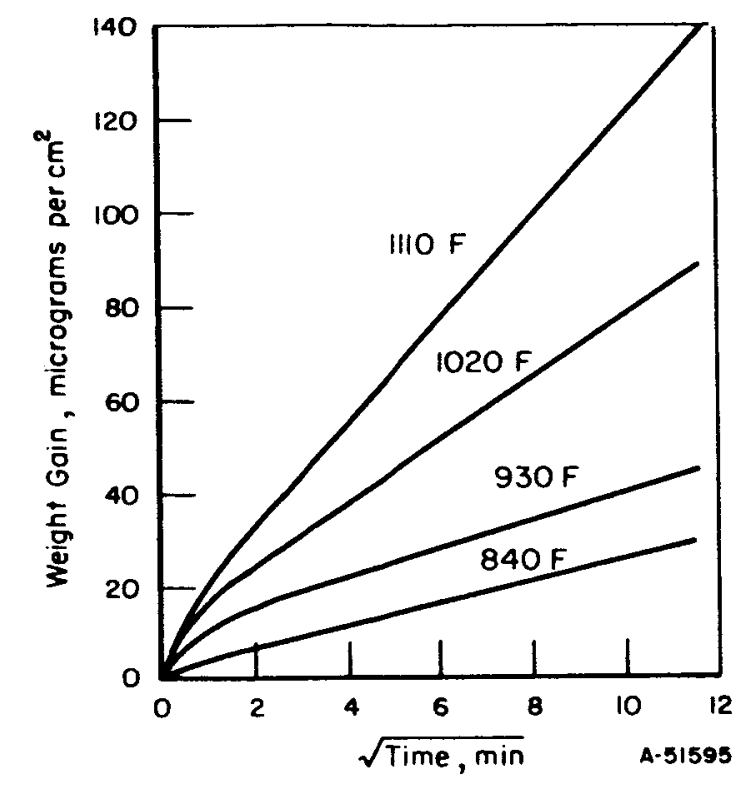

FIGURE 24. OXIDATION RATES OF TITANIUM IN OXYGEN IN THE 800 TO 1100 F RANGE (REF. 11)

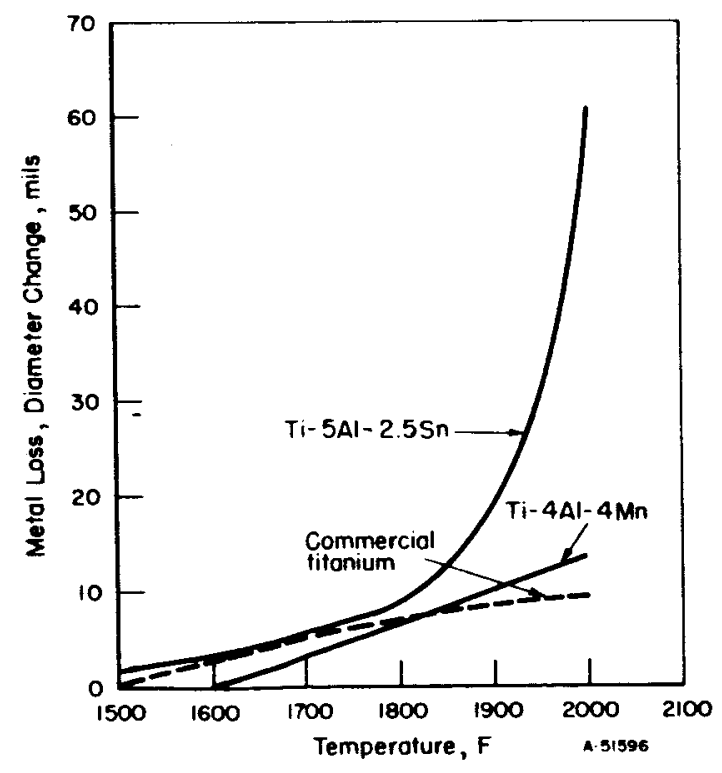

FIGURE 25. COMPARISON OF THE METAL LOSSES OF COMMERCIAL TITANIUM, Ti-5A1-2.5Sn, AND Ti-4Al-4Mn HEATED IN AIR FOR 8 HOURS (REF. 11) 
nor at temperatures up through about $1000 \mathrm{~F}$. Thus, oxidation of titanium in the service-temperature range is not a problem. In fact, it would take about 300 years to form an oxide layer 1 mil thick on titanium at $500 \mathrm{~F}$, or about 6 months at $900 \mathrm{~F}$. However, at higher temperatures, particularly those used for fabrication and heat treatment of titanium, the oxidation rate becomes significant and, in addition, oxygen diffuses into the solid metal. Table IV shows the effect of temperature on the oxide-film thickness of titanium.

TABLE IV. EFFECT OF TEMPERATURE ON THE OXIDE-FILM THICKNESS OF COMMERCIALLY PURE TITANIUM HEATED IN AIR FOR $1 / 2$ HOUR (REF, 1)

\begin{tabular}{|cc|}
\hline Temperature, $F$ & $\begin{array}{c}\text { Measurable Oxide Thickness, } \\
\text { mils }\end{array}$ \\
\hline 600 & None \\
800 & None \\
1000 & None \\
1200 & $<0.2$ \\
1400 & 0.3 \\
1500 & $<1$ \\
1700 & $<2$ \\
1800 & 2 \\
1900 & 4 \\
2000 & 14 \\
\hline
\end{tabular}

Both the oxidation and diffusion processes are time and temperature dependent. At low temperature, $1000 \mathrm{~F}$ and below, the oxidation of titanium follows a parabolic rate law. A protective oxide film is formed, and the oxidation rate decreases with time. In the servicetemperature range (up to $1000 \mathrm{~F}$ ), the oxidation process is selfhealing, and a protective scale is slowly formed. An example of the oxidation rates of titanium at low temperatures is given in Figure 24 .

However, at temperatures in the fabrication and heat-treatment ranges ( 1400 to $2000 \mathrm{~F}$ ), the oxidation rate of titanium and titanium alloys becomes very rapid, as shown by the data in Figure 25 .

More important than oxidation at high temperatures is the diffusion of oxygen into titanium and titanium alloys. The diffusion of oxygen into titanium hardens the surface and causes embrittlement. 
hydrochloric, sulfuric, phosphoric, oxalic, and formic acids), ioniz-. able fluoride compounds, some low-pH salt solutions (including hot, concentrated aluminum and calcium chlorides), and certain powerful oxidizing agents (such as red fuming nitric acid, high concentrations of hydrogen peroxide, liquid and gaseous oxygen), and dry chlorine gas (Ref. 13).

Titanium displays excellent resistance to stress-corrosion cracking in aqueous solutions. Failures a re observed only on rare occasions and then only if the right combination of stress, metallurgical history, and environmental factors is present will the cracks initiate and propagate.

Titanium alloys have a tendency to crack under stress in the presence of chloride salts at a threshold temperature of $550 \mathrm{~F}$ and above. (Refs. 14, 15, 16) This phenomenon has been termed hotsalt stress corrosion. The extent of damage is a direct function of time, temperature, and stress level employed, but it also varies with the alloy and the environment. The phenomenon has been observed in titanium parts which were formed and subsequently heat treated (stress-relief annealing) without proper cleaning prior to heat treatment. Stresses were residual from the forming operation. Chloride ions were believed to be present from either fingerprints or from chlorinated hydrocarbon residues (left by cleaning and degreasing solutions). There is evidence that the residue from chlorinated hydrocarbon solvents contained hydrochloric acid. (Ref. 17) Thus, the importance of proper cleaning to eliminate chloride-containing residues and proper handling to eliminate fingerprinting prior to heat treatment cannot be overemphasized. Mill stencils, oils, and greases should also always be removed from titanium materials prior to pickling, stress-relieving, and annealing operations.

\section{CONTAMINATION CONTROL}

Mill products may be supplied in the annealed condition or in the heat-treated condition. In general, bar stock and forgings can be heat treated to high strength prior to a final grinding or machining operation. In these cases, neither air contamination nor quench distortion presents any great difficulty since the final metal-removal operation gets rid of the contamination or distortion defects. For products of this type, heating in almost any kind of furnace including gas - and oil-fired furnaces, electric miffle furnaces, in a neutral salt bath, or in induction furnaces is suitable. 
The only way that this contamination can be eliminated is by removing the contaminated layer from the surface of the metal.

The oxidation and contamination of titanium alloys do not result in a uniformly hardened case but in a diffusion zone that extends well into the metal. The depth of this zone is both time and temperature dependent. Figure 26 shows the effect of time at $1600 \mathrm{~F}$ on the depth of contamination in unalloyed titanium based on hardness measurements. This type of information is useful in selecting time and temperature combinations for heat-treatment and fabrication operations. Information of this same type is available for titanium alloys from Reference 12 .

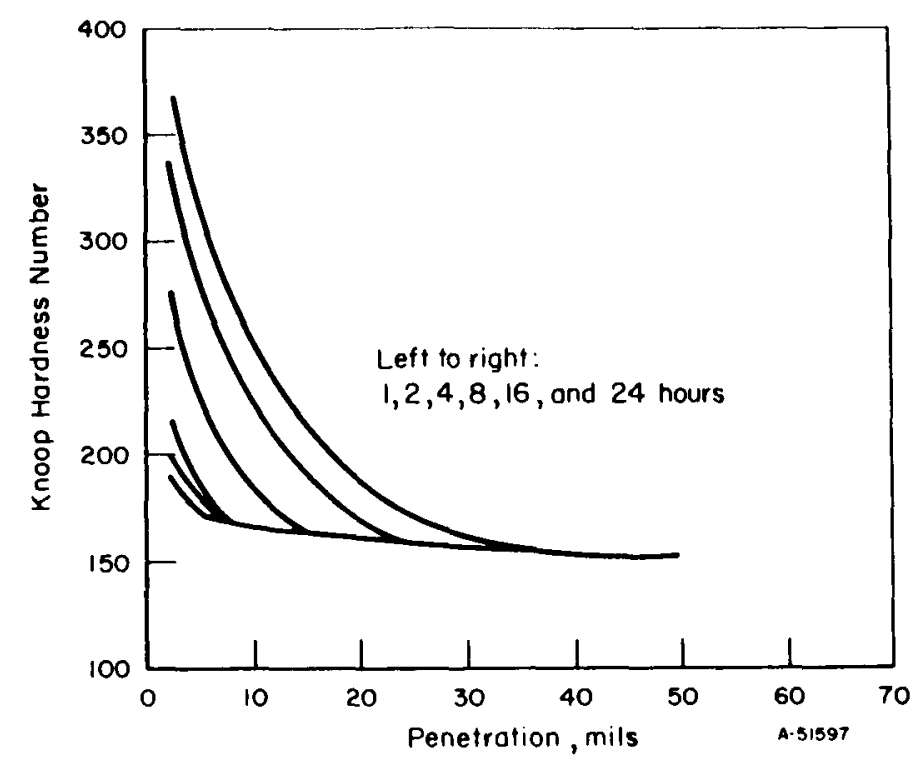

FIGURE 26. SUMMARY OF HARDNESS-PENETRATION DATA FOR UNALLOYED TITANIUM HEATED FOR VARIOUS TIMES IN AIR AT $1600 \mathrm{~F}$ (REF. 11)

Corrosion. Titanium's corrosion properties, unlike those of most metals, can be defined within fairly simple limits. The metal is highly resistant to all natural environments (including seawater, mine waters, body fluids, fruit juices, etc.) and a great many aqueous chemicals up to at least their boiling temperatures. Titanium is used most extensively in environments containing chloride salts, sulfides, hypochlorides, nitric acid, chlorine dioxide, and wet chlorine. (Ref. 13)

Chemicals which attack titanium include hot or concentrated solutions of the reducing type of acids (including some concentrations of 
America is now using a proprietary coating for application to sheet bar that affords good protection and has self-peeling properties at the proper stages of strip rolling. (Ref. 20)

In general, solution-annealing temperatures and times normally recommended for specific alloys result in about 3 to 8 mils depth of contamination. Figures 27, 28, and 29 show curves for estimating the depth of contamination for titanium and two alloys for any given time-temperature conditions. It is generally accepted that the various, commercially available, protective coatings for titanium cut down the depth of contamination but do not eliminate the problem entirely. Unpublished work at Battelle (Ref. 21) indicated that for thin sheet material of $\mathrm{Ti}-6 \mathrm{Al}-4 \mathrm{~V}$, exposed for short periods of time up to $1800 \mathrm{~F}$, contamination was reduced by at least one-half over that of unprotected material. In any case, scale and/or coating must be removed after treatment by chemical milling or by mechanical techniques such as grinding or sandblasting. Titanium Metals Corporation of America reports that the development of a universal effective coating for all titanium alloy substrates is probably out of the realm of practicality. However, specific coating systems have been proven for specific titanium alloys. (Ref. 20) Thus, each individual thermalprocessing treatment must be considered with respect to allowable depth of contamination and to the compatibility and usefulness of any given protective coating. A detailed examination of the surface treatments and conditioning of titanium and titanium alloys, with respect to mechanical, electrochemical, nonmetallic, and spray coatings treatments, is covered in another NASA report. (Ref. 22)

On the basis of recent data, the heat treatment of titanium in a tank of water-soluble molten glass appears attractive for protecting titanium against contamination. (Ref. 23) Solution treating Ti-4Al$3 \mathrm{Mo}-1 \mathrm{~V}$ sheet $1 / 4$ hour at $1625 \mathrm{~F}$ by immersing it in a fritted molten glass $(82.8$ per cent boric oxide-6. 5 per cent alkali oxide-10. 7 per cent alumina) resulted in no surface contamination or any deleterious effect on microstructure. Although glass normally acts as an insulator, specimens heat treated in the above mix and quenched in water from $1625 \mathrm{~F}$ cooled to less than $900 \mathrm{~F}$ within 10 seconds. Residual glass remaining in contact with the alloy can be completely removed in hot (180 F) running water. Considerable additional effort is required before compatibility parameters are firmly established, however, early results appear promising for the use of these molten glasses for protection against contamination.

Descaling has been accomplished by various methods. A sodium hydride or a Virgo bath has been frequently used. (Ref. 7) Titanium 
Near-finished and finished machined parts and sheet titanium present serious heat-treating problems. Unlike steel, titanium cannot be protected from oxidation by conventional atmospheres such as hydrogen, carbon monoxide, or cracked ammonia, since it readily reacts with these gases. Inert gases such as argon and helium can afford protection of finished titanium parts, and even these inert gases must be highly purified, i. e., free from moisture and other trace impurities to avoid contamination of the metal. High-purity gas furnaces are used extensively in laboratories for solution treating of titanium, but commercial furnaces of this type are few. Three alternatives are (1) to solution treat for as short a period as possible, (2) to use the best inert atmosphere economically practical, or (3) to perform the treatment under vacuum. In the former cases, it will be necessary to follow the heat treatment with a pickling or lightgrinding operation. No cleanup should be necessary after vacuum treatment. A word of caution should be interjected here regarding the use of air or inert-gas atmospheres in furnaces that are also used for atmosphere heating of steel. Such furnaces should be purged for several hours with the gas to be used to prevent contamination with hydrogen from residual gas remaining in the crevices and refractory parts of the furnace. In air-blown furnaces, used also for the atmosphere heat treatment of ferrous alloys, an air-flow purge of considerable volume and duration (e.g., $150 \mathrm{cu} \mathrm{ft} / \mathrm{min}$ for 4 hours) is recommended prior to using the furnace for any thermal treatments involving titanium products. (Ref. 18) Of course these oxidation and contamination problems may be circumvented by using vacuum-heattreatment facilities for heat treatments not terminated by rapid cooling.

Perhaps one of the best methods for protecting large titanium parts or sheets of simple geometric configuration is to encapsulate them in low-carbon steel containers. The procedure consists simply of seam welding the steel envelope around the titanium part, putting a fitting in the envelope to permit evacuation of the air, and sealing. (Ref. 18) An alternative to this procedure is to provide two fittings so that a continuous purge of inert gas, such as argon or helium, is presented to the workpiece in the container. (Ref. 19) In either case the steel envelope containing the inert atmosphere protects the titanium from oxidation and hydrogen, and does not seriously affect the cooling rate.

Some organizations, including both producers and end-product fabricators, are using coatings, with varying degrees of success, to protect titanium during thermal treatments. On the other hand, other organizations do not favor coatings. Titanium Metals Corporation of 


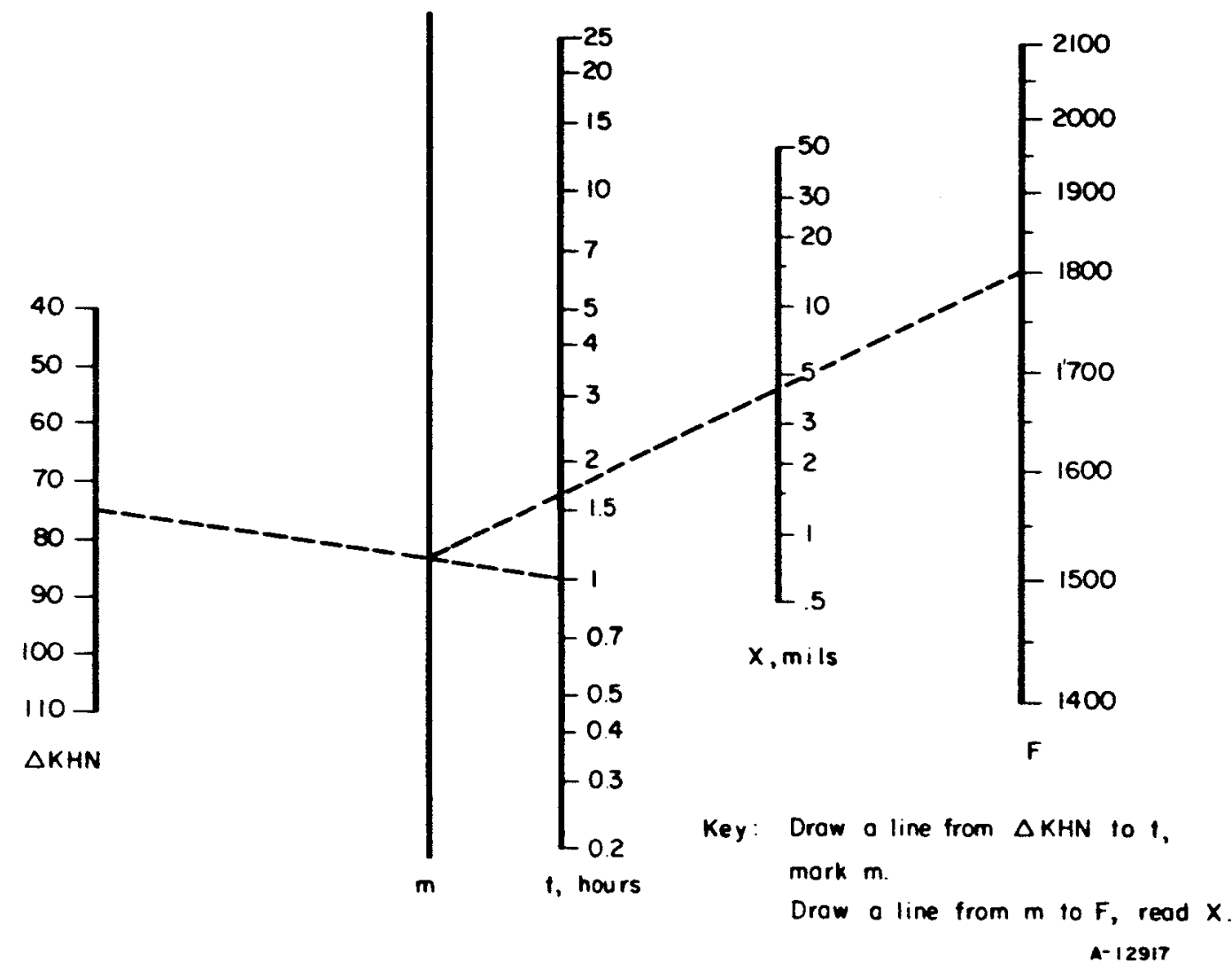

FIGURE 28. NOMOGRAPH FOR ESTIMATING THE DEPTH OF CONTAMINATION OF Ti-5Al-2.5Sn FROM COMBINATIONS OF TIME AND TEMPERATURE OF EXPOSURE TO AIR (REF, 12)

This is based on the solution of $\log x=C+0.5 \log t-$ $\frac{6430}{\mathrm{~T}}$ and $\mathrm{C}=\mathrm{f}(\triangle \mathrm{KHN})$.

Note: The temperature, $\mathrm{T}$, in the equation is in degrees Kelvin. 


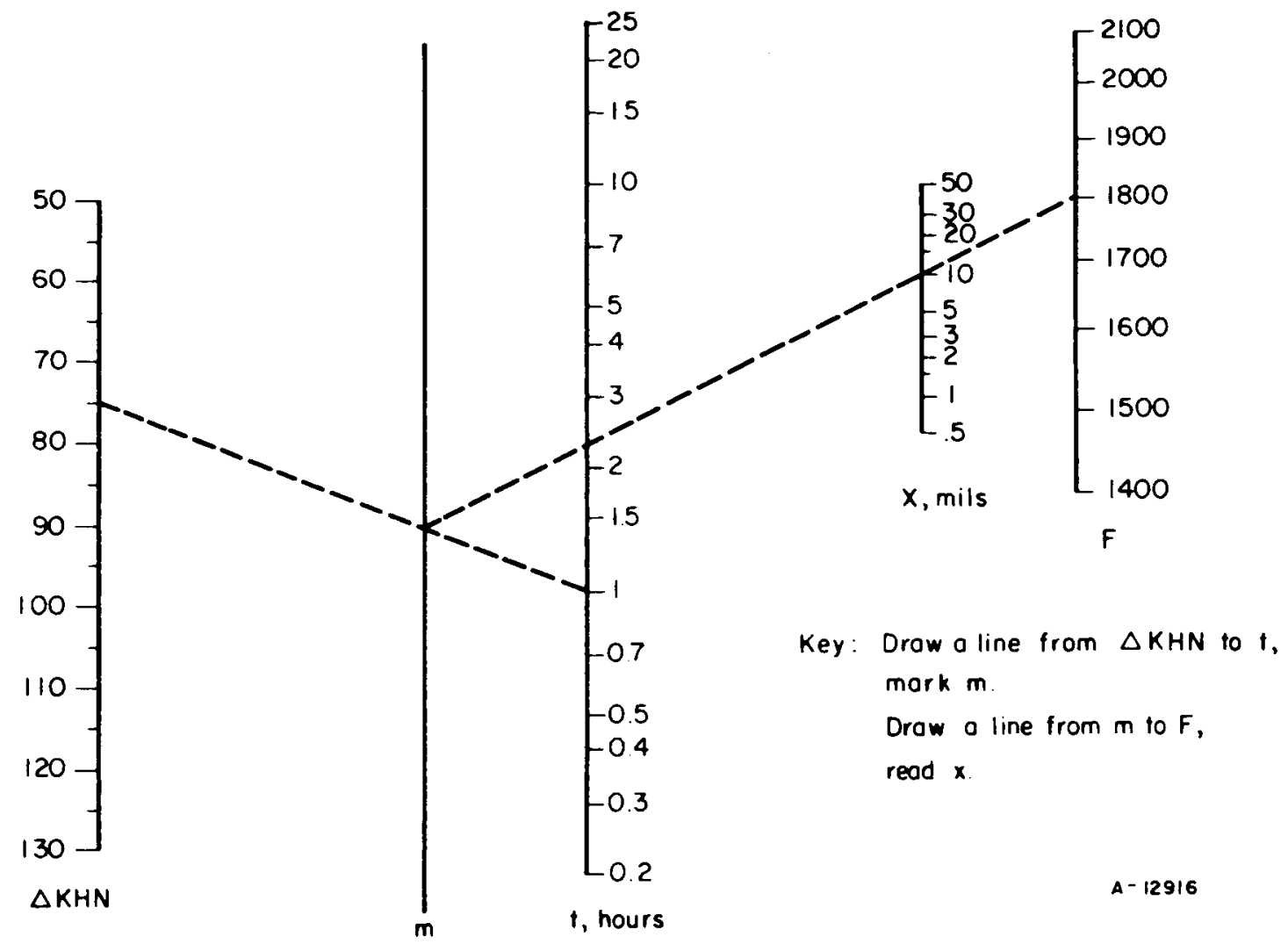

FIGURE 27. NOMOGRAPH FOR ESTIMATING THE DEPTH OF CONTAMINATION OF COMMERCIAL TITANIUM FROM COMBINATIONS OF TIME AND TEMPERATURE OF EXPOSURE TO AIR (REF. 12)

This is based on the solution of $\log \mathrm{x}=\mathrm{C}+0.5 \log \mathrm{t}-$ $\frac{10,700}{\mathrm{~T}}$ and $\mathrm{C}^{\prime}=\mathrm{f}(\triangle \mathrm{KHN})$.

Note: The temperature, $T$, in the equation is in degrees Kelvin. 


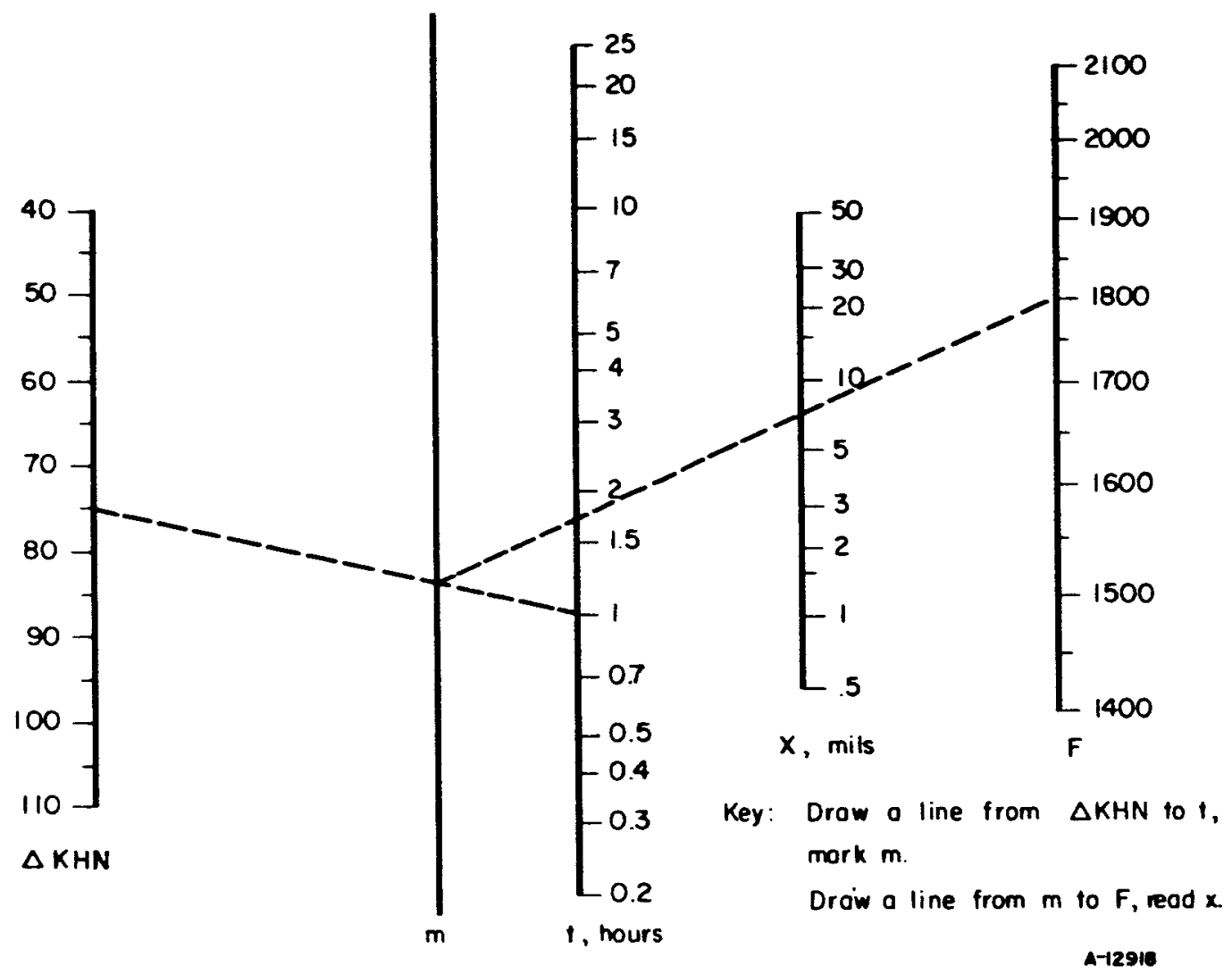

FIGURE 29. NOMOGRAPH FOR ESTIMATING THE DEPTH OF CONTAMINATION OF Ti-4Al-4Mn FROM COMBINATIONS OF TIME AND TEMPERATURE OF EXPOSURE TO AIR (REF, 12)

This is based on the solution of $\log \mathbf{x}=$ $\mathrm{C}+0.5 \log \mathrm{t}-\frac{6050}{\mathrm{~T}}$ and $\mathrm{C}=\mathrm{f}(\Delta \mathrm{KHN})$.

Note: The temperature, $T$, in the equation is in degrees Kelvin. 
Metals Corporation of America uses a low-temperature (400 to $425 \mathrm{~F}$ ) salt bath, composed of potassium compounds with additives and inhibitors to control oxidation, to descale almost all titanium alloys rolled and annealed at 800 to $1900 \mathrm{~F}$. (Ref. 20) Operating at this low temperature, well below the 700 to $1000 \mathrm{~F}$ range common to many salt-bath descaling processes, scale can be removed without age hardening or causing excessive hydrogen pickup. The process is carried out in two batch-type descaling and pickling installations in which billets, slabs, tubing, plate, sheet, and wire are passed through the salt bath, a cold-water rinse, 35 per cent sulfuric acid, a hot-water rinse, and finally through a nitric-hydrofluoric acid solution and another hot-water rinse. Short, repetitive cycles about 10 minutes in the salt bath and 5 minutes in the sulfuric acid have proved to be more effective than one longer cycle.

Shot blasting and grinding also have been used to descale titanium alloys. Pickling is accomplished nearly universally in a $\mathrm{HF}-\mathrm{HNO}_{3}$ water solution at slightly elevated temperatures. Although this solution will also cause hydrogen pickup, it is now standard practice to minimize this by maintaining the $\mathrm{HF}$ concentration below about 3 per cent and the $\mathrm{HNO}_{3}$ concentration above about 15 per cent. Too high a concentration of $\mathrm{HNO}_{3}$ will create fuming and make the bath difficult, if not dangerous, to handle. (Ref. 7)

In summary, a few points should be reemphasized regarding the mechanics of titanium heat treatment. Titanium is chemically very active at elevated temperatures, and reacts readily with oxygen, nitrogen, carbon, and hydrogen in a furnace atmosphere. In all heattreating operations, oxidation can be a very important factor, due to the embrittling effect of titanium oxides on the properties of a part. Primarily because of oxidation, heating times are kept as short as is required to perform the heat treatment. This is particularly true for sheet products, where the surface to volume ratio is large and the difficulty of scale removal is the greatest. Most titanium forgings are fully machined after hot working and heat treatment. Some forgings are ground or otherwise machined to remove contamination only in the areas of high-stress concentration. (Ref. 1)

The danger of hydrogen pickup during heat-treating operations is probably more important. Current specifications limit hydrogen concentrations in titanium alloys to under $200 \mathrm{ppm}$. At high hydrogen concentrations, the titanium becomes embrittled, showing a reduced impact and notched tensile strength. To minimize the possibility of hydrogen pickup or to avoid oxidation, heat treatment is sometimes accomplished in an inert atmosphere such as argon or helium, or 
in a vacuum. Because these methods are expensive, most heat treating is done in a slightly oxidizing atmosphere; this reduces the partial pressure of hydrogen that may be in the surrounding atmosphere from the breakdown of water vapor or unburned hydrocarbons. (Ref. 1)

Oxidation rates vary with the titanium alloy. Generally $\alpha$-alloys show slightly less scaling than $\beta$-alloys. Nitrogen is absorbed by titanium during heat treatment at a much slower rate than oxygen, and does not produce a serious contamination problem. (Ref. 1)

Titanium alloys are also subject to stress corrosion when exposed to chlorides at temperatures above about $550 \mathrm{~F}$ in the presence of an applied or residual tensile stress. Fingerprints or chlorides from cleaning solutions must be cleaned off of the titanium part prior to heat-treatment operations. (Ref. 1)

In addition, since titanium materials are very reactive at normal heat-treating temperatures, care must be exercised to eliminate mill stencils, oils, and greases prior to stress relief and annealing operations. The reaction of certain furnace refractories and mill scale carried over from ferrous heat-treating operations with titanium materials should also be carefully considered and removed if possible before any thermal treatments are performed.

\section{FURNACING}

In discussing furnaces for the heat treatment of titanium, a review of the practices followed by titanium producers, fabricators, and users affords an insight into the most acceptable methods of heating titanium.

Since the production of titanium mill products has been carried out almost entirely in facilities which are owned and operated by steel companies, the heating and heat-treating equipment used for steel have also been used for titanium. This has been a rather satisfactory arrangement since the temperatures required for shaping and heat treating of titanium are not very different from those used for steel products. Unlike steel, titanium and its alloys are very reactive with the atmosphere at mill-processing and heat-treating temperatures as explained earlier in this report.

Titanium ingots and semifinished products are heated and forged or rolled with and without protection from the air. Proprietary coatings are used in many of the primary metalworking operations 
although not universally so. Heating may be carried out in any type. of furnace, and gas- or oil-fired furnaces commonly found in steel plants have been used with success. The most important precaution to be observed with fuel furnaces is that the stock should not be exposed directly to the flame if this can be avoided. If complete muffling is not possible, the atmosphere in the furnace should be free from water vapor and should be slightly oxidizing. Both water vapor and incompletely burned fuel vapor can react with titanium to form atomic hydrogen which is readily absorbed by the titanium. Thus, one of the principal sources of hydrogen contamination in titanium products is the fuel-fired furnace. The only practical method for removing hydrogen from titanium is by vacuum annealing. Furnaces for solution treating may be gas fired or electric, with the latter being preferred to minimize hydrogen pickup. Resistance and induction types of heating arrangements are also used to minimize contamination through reduced heating times. The effectiveness of a solution-treatment operation is tied very closely to the way the quenching medium operates in conjunction with the furnace. In many cases of production parts, the furnaces are built together so that the part can be dropped or rolled from the hot zone into the quenching area in a very short time. Quench delay time is critical with regard to obtaining optimum properties. Water is the most widely used quenching medium, although low-viscosity oil and water containing about 3 per cent $\mathrm{NaOH}$ are also employed. (Ref. 1) The $\mathrm{NaOH}$ addition provides for a better wetting action and consequently more efficient heat dissipation. (Ref. 18) There have been some reports that solution-treated and aged $\mathrm{Ti}-6 \mathrm{Al}-4 \mathrm{~V}$ exhibits considerable improvements in strength combined with good ductility when more effective water-quenching techniques are employed. (Ref. 24) It appears that this is facilitated for titanium alloys by incorporating the correct quench media with violent agitation through an oversized pumping system. (Ref. 18) For example, if a 5-hp pump is sufficient to agitate a bath, a much larger pump, say 50-hp, might truly be required to more ideally quench the part for optimum property development.

Vertical gantry types of furnaces are quite popular for the heat treatment of titanium. (Refs. 18, 25) These furnaces are normally electric or gas fired with a maximum operating temperature of 2000 to $2100 \mathrm{~F} \pm 25 \mathrm{~F}$. Effective working areas of up to at least 29 feet in height (Ref. 25) and 13 feet in diameter are available. Quench tanks are located in pits below the floor and the furnace travels on a track to the particular quench tank in use. Transfer time from furnace to quench media can be accomplished in less than 5 seconds. Sheet quenched from vertical furnaces is relatively free from 
dịstortion because it is suspended vertically. However, very short transfer times can cause degradation of the part through mechanical vibration caused by speeding up the quenching process. (Ref, 18) California-Doran Heat Treating Company has found in solution treating $\mathrm{Ti}-6 \mathrm{~A} 1-4 \mathrm{~V}$ heavy section parts that no detriment in properties occurs when using up to an 8-second quench delay time provided the cooling rate is very rapid once the part enters the quench medium. (Ref. 18) A vertical furnace of this type used in the heat treatment of titanium is shown in Figure 30 .

Very large gas-fired furnaces, such as the one shown in Figure 31, are available for stress relieving and aging of titanium parts and structures. Creep flattering of large titanium plates has been proposed using this type of furnace.

Although vacuum heat treatment is normally more expensive than conventional furnacing, many applications of titanium heat treatment are ideally suited for vacuum. Many times when comparing various heat-treatment processes in their entirety, the vacuum treatment becomes more economical since problems associated with contamination and necessary cleanup are eliminated. Of course, final machined parts and thin-sheet structures requiring high-temperature thermal exposure while maintaining close dimensional tolerances are excellent candidates for vacuum furnaces. Also, the only practical way of lowering detrimental hydrogen content in titanium materials is by vacuum exposure. This is usually done at a temperature between 1000 and $1400 \mathrm{~F}$ for 2 to 4 hours at pressures of less than $0.5 \mathrm{mic}-$ ron. (Ref. 26) Under these conditions, chemically milled and hydrogen-contaminated $\mathrm{Ti}-6 \mathrm{Al}-4 \mathrm{~V}$ containing 550-ppm hydrogen can be purified to 25 to $35-\mathrm{ppm}$ hydrogen after vacuum treatment. (Ref. 26)

Vac-Hyd Corporation has a very large vacuum furnace that is being used for titanium heat treatment. (Ref. 26) The furnace measures 5 feet in diameter, 5 feet high (5-1/2 feet with a lower temperature retort), and can maintain heat-treatment temperatures up to $2250 \mathrm{~F}$ (maximum) at 0.1 to 0.3 micron. Heating elements are contained outside the evacuated retort. Thin titanium sheet, 30 to 40 mils, is normally used as a getter to protect the titanium parts. These titanium shields are mounted around the workpiece and are used five times before recleaning. Cooling is normally slow. However, an argon back-fill can be used to give a quench rate of $100 \mathrm{~F} / \mathrm{minute}$. Vac-Hyd has plans for a production vacuum unit capable of quenching from vacuum which will duplicate an oil quench. 

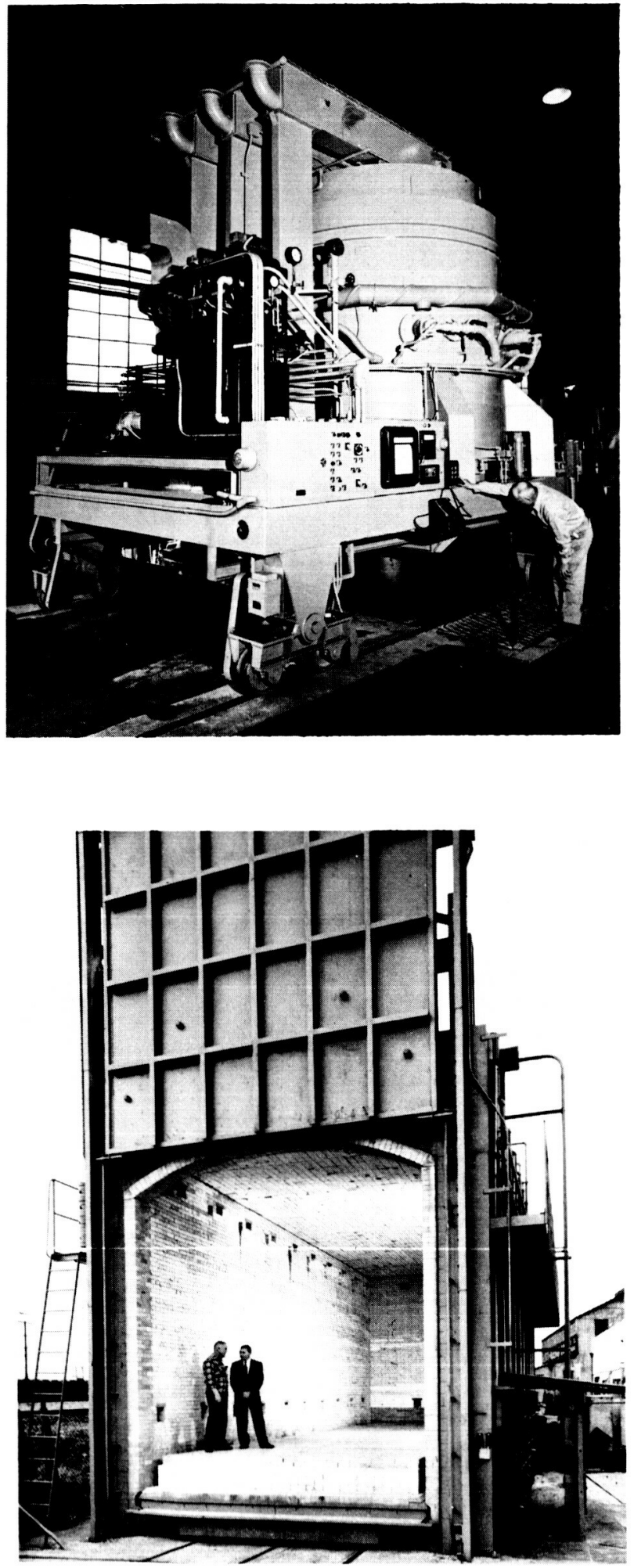

FIGURE 30. VERTICAL GANTRY TYPE OF FURNA CE

\author{
6 feet in dianneter, 8 feet - \\ 6 inches high, $2000 \mathrm{lb}$ at \\ $2000 \mathrm{~F}$ or $3000 \mathrm{lb}$ at $1600 \mathrm{~F}$, \\ $\pm 5 \mathrm{~F}$ gradient.
}

Courtesy of California-Doran Heat Treating Co.
FIGURE 31. CAR BOTTOM TYPE OF FURNACE

Furnace measures 12 feet by 12 feet by 42 feet.

Courtesy of CaliforniaDoran Heat Treating Co. 
- Salt baths, such as $\mathrm{NaCl}$ or $\mathrm{BaCl}_{2}$, are and have been used in the solution treatment of titanium parts. However, some experience in the application of a neutral $\mathrm{BaCl}_{2}$ salt bath during solution annealing resulted in intergranular attack of the titanium, such that excess material was required to allow for contamination cleanup. If excess material is available, the heat treatment can normally be effected better in air. (Ref. 18) In addition, the salt-bath residue, if not properly and completely removed, may have adverse effects in promoting salt stress corrosion as discussed earlier in this report.

For the production heat treatment of flat-rolled mill products, Titanium Metals Corporation of America has a continuous electricroller hearth furnace outfitted with roller-leveler-spray-quench apparatus on one end and a 16-foot-long tank at the other. (Ref. 1) Production sheets are heated.to the solution-treating temperature, going through a preheat zone first. They are finally held at the solution temperature for about 5 minutes and then heavily spray quenched, top and bottom, as they emerge from the furnace just before they enter the roller leveler and also during roller leveling. The three zones in this furnace are controlled to $\pm 5 \mathrm{~F}$, and the temperature is uniform in each zone. The roller-spray-quench apparatus is designed to provide an even quench, and is positioned to minimize the transfer time from furnace to quench.

Titanium Metals Corporation of America also has a continuousvacuum-annealing furnace in operation in conjunction with a Sendzimer Mill, and other cutting and cleaning equipment for the production of commercially pure and alloy strip. (Ref. 1) Strip to be intermediate or final annealed enters the furnace tower through a series of rollers, coming first to a cold zone. It then passes into the hot zone in the top, front quadrant of the tower. After annealing, the strip passes over rollers in the top of the furnace and down the back side; the back half of the furnace is also cold. Vacuums in the chambers are in the 0.1 to 0.5 -micron pressure range. Strip up to 48 inches wide may be accommodated. This continuous-vacuumannealing equipment is a tremendous improvement over conventional line air-annealing techniques, as postanneal descaling is avoided, along with the gage control and pitting, and other problems it creates.

\section{HEAT TREATMENT TECHNIQUES}

There are several reasons for heating titanium parts back up to elevated temperatures after the primary fabrication of mill products. 
Secondary fabrication, that is metal shaping, is the foremost reason. and various heat treatments for the development of optimum properties account for the remainder. Some of the difficulties and problems that might be encountered, and some of the solutions to these situations have been reviewed in the preceding sections. Thus, it remains to review some of the operations required to heat-treat titanium using techniques that have been found to give successful finished parts.

Four distinct types of heat treatment need be considered: stress relief annealing, full annealing, solution annealing or solution heat treatment, and aging. As described in the metallurgical sections of this report, some titanium alloys are not given all types of treatments, and in practice all types of treatments are never used in producing a single part even though the alloy used might be amenable to all four types. For example, the Ti-6Al-4V alloy may be given all four heat treatments, but this is never done in producing $\mathrm{Ti}-6 \mathrm{Al}-$ $4 \mathrm{~V}$ parts. Instead, the alloy is used in one of several conditions as follows.

(1) Ti-6Al-4V mill product supplied from the mill in the annealed condition

(a) May be shaped and conditioned to final part size then used without any additional heat treatment

(b) May be shaped and conditioned to final part size then stress-relief annealed prior to use

(c) May be shaped (drastic deformation) and conditioned to final part size then fully reannealed prior to use

(d) May be shaped and solution heat treated, quenched, conditioned to final part size, and aged prior to use

(e) May be solution heat treated, quenched, shaped and conditioned to final part size, and aged prior to use. 
- (2) Ti-6Al-4V mill product supplied from the mill in the solution-heat-treated condition

(a) May be shaped and conditioned to final part size and then aged prior to use

(b) May be shaped (drastic deformation) resolution heat treated, quenched, conditioned to final part size, and aged prior to use.

(3) Ti-6Al-4V mill product supplied in the solution-treatedand-aged condition

(a) May be used without additional heat treatment

(b) May be mildly deformed and shaped by additional aging in fixtures prior to use.

Note: As is discussed later in this section, stress-relief annealing and aging heat treatments can be incorporated into the forming operation.

In the case of non-heat-treatable titanium grades, such as unalloyed grades and $\alpha$-alloys, only stress-relief annealing or full reannealing treatments are used to condition the part for use. There are no metallurgical reasons for solution treating and aging grades of this type.

Until recently, the high-temperature (as in solution heat treatment) heat treatment of titanium was not utilized by titanium users. Instead, most of the titanium used was in the annealed or stressrelief-annealed condition, or else, in a few cases, users aged the material after forming from a producer-supplied solution-annealed condition. With the advent of rocket technology, solution heat treatment of titanium parts (and subsequent use in the aged condition) became more common among titanium users. At first, and still the predominant practice today, heavy section parts were those most frequently destined for use in the higher strength, solution-treated, quenched, and aged condition. The practice was to shape, rough machine (leaving considerable excess stock), solution heat treat, quench, finish machine and otherwise finish the fabrication, and age. The heavier contamination picked up during solution heat treatment was removed by the finish-machining operation while light contamination, often just a surface tarnish, picked up during aging was eliminated by various chemical and mechanical methods. Heat 
treatment in air was, and is, the most common practice, although there is definitely a trend toward more usage of the sophisticated heat-treatment techniques, inert gas or vacuum protection from the contaminates.

At a somewhat later point in time, solution heat treatment and aging to develop high strength in titanium alloys, started to be applied to all sorts of titanium parts including sheet parts. For example, the XB-70 represents the first application of heat-treated titanium-alloy sheet for airframe structures. In this case, the transition from fabrication of the lower strength, annealed, commercially pure and $\mathrm{Ti}-8 \mathrm{Mn}$ materials to that of higher strength, heat-treated $\mathrm{Ti}-6 \mathrm{Al}-4 \mathrm{~V}$ and $\mathrm{Ti}-4 \mathrm{Al}-3 \mathrm{Mo}-1 \mathrm{~V}$ was accomplished. The forward fuselage of the XB-70 consists almost entirely of the above materials, in addition to heat-treated $\mathrm{Ti}-6 \mathrm{Al}-4 \mathrm{~V}$ forgings and extrusions and heat-treated Ti-7Al-4Mo bar and forgings. In these upto-date applications, the alloys are heat treated to their maximum tensile-strength levels of 160,000 to $200,000 \mathrm{psi}$ and used as sheet, bar, extrusions, and forgings in many sizes and configurations. In each part, the alloys are selected and processed to achieve maximum strength, closely controlled fracture toughness, and close dimensional tolerances. (Ref. 27)

Forming, for the production of precision XB-70 parts in heattreated materials, is a highly refined process, involving roomtemperature forming and hot sizing at about $1200 \mathrm{~F}$ in precision metal dies (Figure 32). This is necessary to compensate for the low amount of plasticity and the very high spring-back rate of highstrength titanium. A final aging cycle develops the 170,000-psi strength level in the parts. (Ref. 27)

Elsewhere in the industry, hot sizing and creep forming are also becoming commonplace. The further advancement of incorporating either simultaneous sizing - stress-relief annealing or creep forming - aging schedules into the production of parts is being made. (Ref. 25) These operations are usually accomplished in air, since temperatures are not high enough to result in severe contamination, although as noted earlier, there is a trend to more and more usage of protective devices that minimize contamination. 

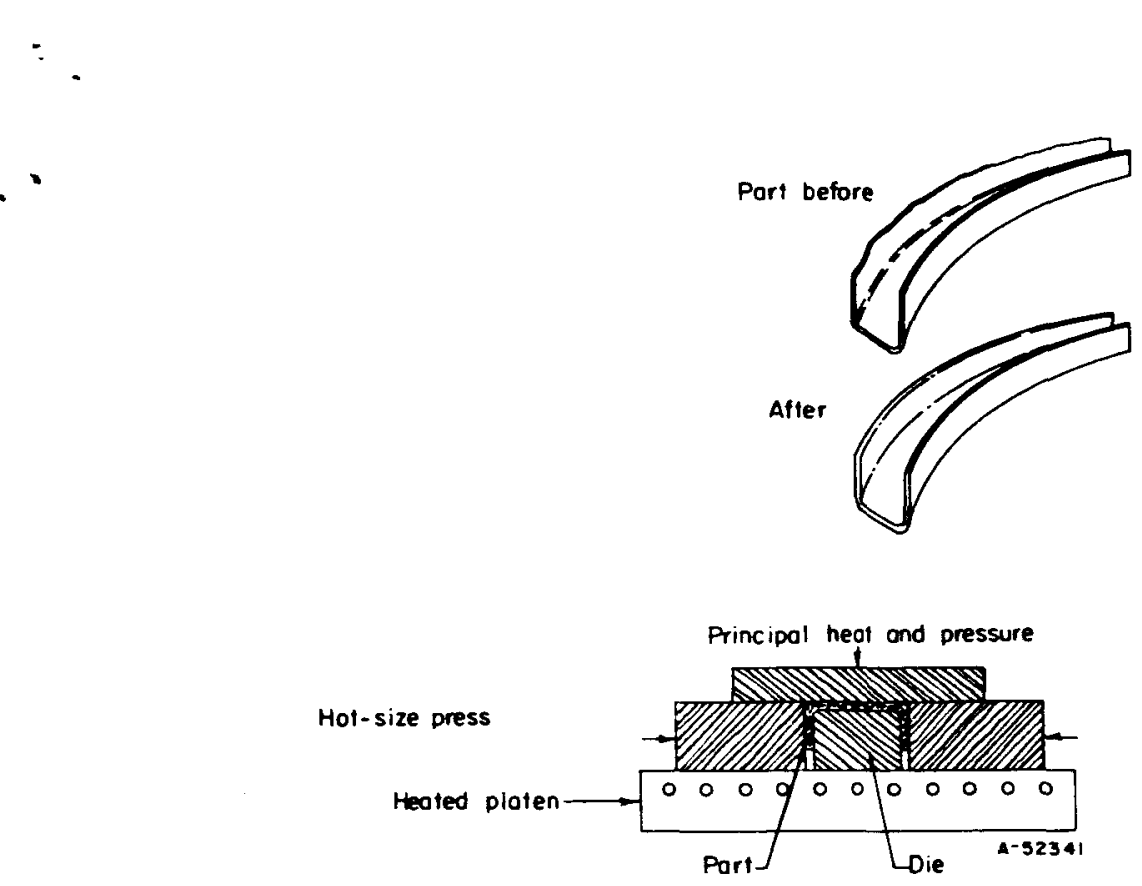

FIGURE 32. HOT SIZING OF TITANIUM (REF. 27)

Most titanium parts and structures are fixtured in jigs constructed of iron-base or nickel-base alloys to prevent distortion during heat treatment. (Refs. 18, 19, 25, 26) It is generally recommended that the titanium part be separated from the fixtures by thin titanium sheet (Ref. 26) or sprayed $\mathrm{Al}_{2} \mathrm{O}_{3}$ (Ref. 25) to prevent any possible contamination from the jigging. Prior to use, the fixtures are usually thoroughly cleaned and "burned off" in air or vacuum, depending upon the method of heat treatment.

Stress relieving is used extensively to remove high residual stresses induced during forming and fabrication operations. It is also being used to remove warpage from formed parts and from sheet or parts that are distorted after solution treating. In some cases, the stress-relieving forming operation is also a part of the aging cycle.

In the past, Boeing (Ref. 7) investigated the extent of warpage removal that occurs when $\mathrm{Ti}-6 \mathrm{Al}-4 \mathrm{~V}$ parts are restrained during a stress-relief heat treatment. First, the theoretical stress relief that occurs when the alloy is exposed to various temperatures for different times was determined. The results are plotted as the monograph shown in Figure 33. Data of this type may be used as a guide for predicting warpage removal in a given part, but allowance must be made for configuration. Boeing points out that the extent of warpage removal is roughly proportional to the structural stability of the part. Thus, in narrow flat strips warpage removal will be very close to the percentage of stress relief indicated on the monograph; 


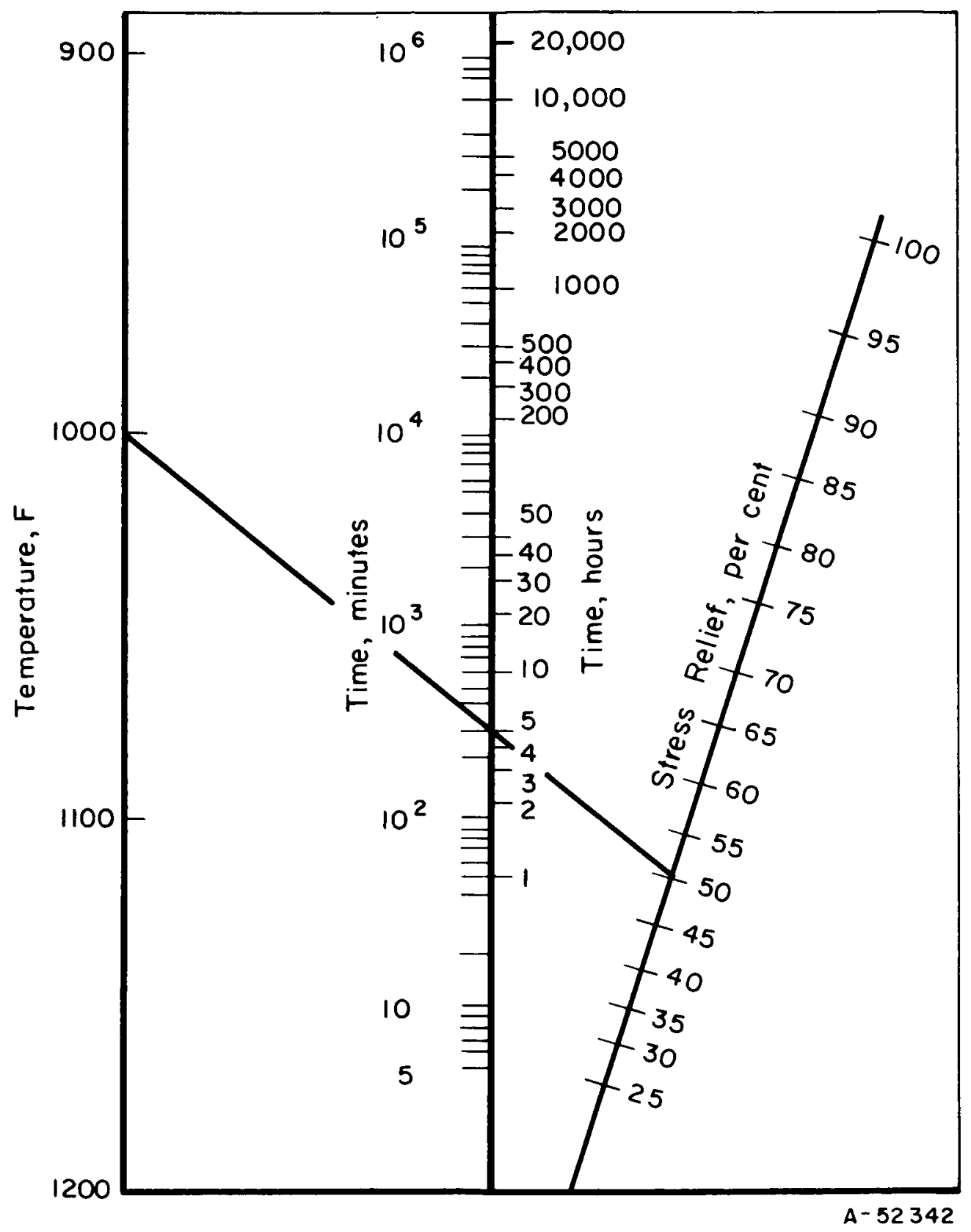

FIGURE 33. TIME-TEMPERATURE-PER CENT STRESS RELIEF RELATIONSHIP FOR Ti-6Al-4V (REF. 7) 
however, in formed parts the warpage removal would be greater. The difference is due primarily to the very high stresses created by clamping the formed part.

\section{CONCLUSIONS AND RECOMMENDATIONS}

This review of present practices for heat-treating titanium alloys brings out several areas which require additional research and development.

With the increased demands and uses of titanium materials, a continued effort is required to disseminate practical information which describes the proper technique normally employed in handling titanium alloys. A continued practical program of this type would eliminate many problems encountered by the initiate such as heat treatment in incorrect atmospheres (i. e., hydrogen or nitrogen).

A more comprehensive and practical approach to reduce contamination of titanium alloys during heat treatment is needed. The need for better and more compatible protective coatings which reduce or prevent contamination is especially great. Furthermore, the development of nonreactive molten baths, such as salts and glasses, would permit a most economical technique for heat-treating titanium alloys.

It appears that prior research and development work which established specifications for the quench delay and quench rates of titanium alloys has neglected the practical aspects of adapting these parameters to large-scale production heat treatments. For example, rapid transfer times of large titanium parts to the quench media can result in severe deformation of parts due to handling problems that could have been avoided by relaxing the transfer time by only a few seconds. . (Large, thick section parts do not require extremely short quench delay times because they do not lose heat quickly.) In addition, work is required to better establish the effect on the properties of titanium alloys as a function of quench-media, volume available, and amount of agitation.

A relaxation of the aging-time specification of titanium alloys is required. This would allow the heat treatment of complex titanium parts and shapes in the creep-form-aging operation to be done under a more realistic and practical set of conditions to meet required dimensional specifications. 


\section{REFERENCES}

1. Broadwell, R. G., "The Practical Heat Treatment of Titanium Alloys", paper presented at the Titanium Metallurgy Course, New York University, School of Engineering and Science (September 13-15, 1965) (RSIC 1264).

2. Maykuth, D. J., Holden, F. C., Williams, D. N., Ogden, H. R., and Jaffee, R. I., "The Effects of Alloying Elements in Titanium, Vol. B. Physical and Chemical Properties, Deformation and Transformation Characteristics", DMIC Report 136B, Battelle Memorial Institute (May 29, 1961) (RSIC 1291).

3. Maykuth, D. J., Ogden, H. R., and Jaffee, R. I., "The Effects of Alloying Elements in Titanium, Vol. A. Constitution", DMIC Report 136A, Battelle Memorial Institute (September 15, 1960) (RSIC 1292).

4. Aircraft Designer's Handbook for Titanium and Titanium Alloys, SST 65-8, Contract FA-SS-65-6, prepared for Federal Aviation Agency by Battelle Memorial Institute (August, 1965) (RSIC 0575).

5. Faulkner, G. E., Lewis, W. J., and Martin, D. C., "The Status and Properties of Titanium Alloys for Thick Plate", DMIC Report 185, Battelle Memorial Institute (June 14, 1963) (RSIC 0693).

6. McQuillan, A. D., and McQuillan, M. K., Titanium, Metallurgy of the Rarer Metals-4, Butterworth \& Co. (Publishers) Limited (RSIC 0600).

7. Griest, A. J., and Frost, P. D., "Principles and Application of Heat Treatment for Titanium Alloys", TML Report No. 87, Battelle Memorial Institute (December 27, 1957) (RSIC 1265).

8. Minkler, W. W., "Titanium in 1965", paper presented at the Titanium Metallurgy Course, New York University, School of Engineering and Science (September 13-15, 1965) (RSIC 1308).

9. Wood, R. A., "A Tabulation of Designations, Properties, and Treatments of Titanium and Titanium Alloys", DMIC Memorandum 171 (Revision of DMIC Memorandum 10), Battelle Memorial Institute (July 15, 1963) (RSIC 0293). 
.10. Wood, R. A., "Effect of Interstitials on the Mechanical Properties of Titanium and Its Alloys", paper presented at the Titanium Metallurgy Course, New York University, School of Engineering and Science (September 13-15, 1965) (RSIC 1302).

11. Ogden, H. R., "The Behavior of Titanium at Elevated Temperatures", paper presented at the Titanium Metallurgy Course, New York University, School of Engineering and Science (September 13-15, 1965) (RSIC 1301).

12. Reynolds, J. E., Ogden, H. R., and Jaffee, R. I., "A Study of the Air Contamination of Three Titanium Alloys", TML Report No. 10, Battelle Memorial Institute (July 7, 1955) (RSIC 1335).

13. Bomberger, H. B., "Fundąmentals of Corrosion of Titanium", paper presented at the Titanium Metallurgy Course, New York University, School of Engineering and Science (September 13-15, 1965) (RSIC 1304).

14. Braski, D. N., and Heimerl, G. J., "The Relative Susceptibility of Four Commercial Titanium Alloys to Salt Stress Corrosion at 550 F", NASA TN D-2011, National Aeronautics and Space Administration (December, 1963) (RSIC 1306).

15. Pride, R. A., and Woodard, J. M., "Salt-Stress-Corrosion Cracking of Residually Stressed Ti-8Al-1Mo-1V Brake-Formed Sheet at $550 \mathrm{~F}(561 \mathrm{~K})$ ", NASA TM X-1082, National Aeronautics and Space Administration (April, 1965) (RSIC 1307).

16. Boyd, W. K., and Fink, F. W., "The Phenomenon of Hot-SaltStress-Corrosion Cracking of Titanium Alloys", NASA CR-117, Contract No. NASr-100(04), prepared by Battelle Memorial Institute for the National Aeronautics and Space Administration (October, 1964) (RSIC 1184).

17. Pearson, R. E., "Fundamentals of Design Considerations", paper presented at the Titanium Metallurgy Course, New York University, School of Engineering and Science (September 13-15, 1965) (RSIC 1303).

18. Private communication with $R$. H. Lundquist of California-Doran Heat Treating Company, Los Angeles, California (October 13, 1965) (RSIC 1333). 
19. Private communication with S. Smith of Menasco Manufacturing . Company, Burbank, California (October 12, 1965) (RSIC 1330 ).

20. Private communication with G. A. Lenning of Titanium Metals Corporation of America, Henderson, Nevada (October 13-14, 1965) (RSIC 1334).

21. Private communication with R. H. Ernst and D. N. Williams of Battelle Memorial Institute, Columbus, Ohio (October 18, 1965) (RSIC 1328).

22. Mallett, M. W., "Surface Treatment and Conditioning of Titanium and Titanium Alloys", unpublished report prepared by Battelle Memorial Institute for Redstone Scientific Information Center under Contract DA-01-021-AMC-11651 (Z). (RSIC 1327).

23. Unpublished data under Contract AF 33(615)-1386, North American Aviation, Columbus Division (January-June, 1965) (RSIC 1305).

24. Private communication with $\mathrm{H}$. Gilbert and J. J. Shaw of Harvey Aluminum Company, Torrance, California (October 13, 1965) (RSIC 1332).

25. Private communication with K. T. McDonald of North American Aviation, Los Angeles, California (October 12, 1965) (RSIC 1329).

26. Private communication with $\mathrm{H}$. A. Kraake of Vac-Hyd Corporation, Torrance, California (October 13, 1965) (RSIC 1331).

27. Rogerson, D. B., "Technological Advancements Resulting from XB-70 Performance Requirements", paper presented at the National Aeronautic and Space Engineering and Manufacturing Meeting, SAE 650798, Los Angeles, California (October 4-8, 1965) (RSIC 1343). 
HEAT TREATMENT OF TITANIUM AND TITANIUM ALLOYS

By F. F. Schmidt and R. A. Wood

The information in this report has been reviewed for security classification. Review of any information concerning Department of Defense or Atomic Energy Commission programs has been made by the MSFC Security Classification Officer. This report, in its entirety, has been determined to be unclassified.

This document has also been reviewed and approved for technical accuracy.

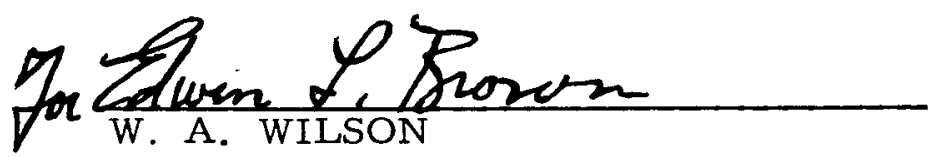

Chief, Methods Development Branch

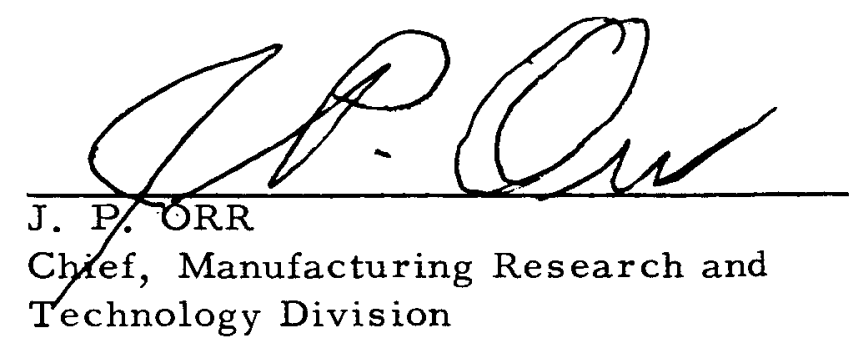

\footnotetext{
thrubn

for WERNER R. KUERS

Director, Manufacturing Engineering

Laboratory
} 